\title{
Multi-generation gas-phase oxidation, equilibrium partitioning, and the formation and evolution of secondary organic aerosol
}

\author{
C. D. Cappa ${ }^{1}$ and K. R. Wilson ${ }^{2}$ \\ ${ }^{1}$ Department of Civil and Environmental Engineering, University of California, Davis, CA 95616, USA \\ ${ }^{2}$ Chemical Sciences Division, Lawrence Berkeley National Laboratory, Berkeley, CA 94720, USA
}

Correspondence to: C. D. Cappa (cdcappa@ucdavis.edu)

Received: 11 January 2012 - Published in Atmos. Chem. Phys. Discuss.: 31 January 2012

Revised: 18 July 2012 - Accepted: 25 September 2012 - Published: 22 October 2012

\begin{abstract}
A new model of secondary organic aerosol (SOA) formation is developed that explicitly takes into account multi-generational oxidation as well as fragmentation of gasphase compounds, and assumes equilibrium gas-particle partitioning. The model framework requires specification of a limited number of tunable parameters to describe the kinetic evolution of SOA mass, the average oxygen-to-carbon atomic ratio and the mean particle volatility as oxidation proceeds. These parameters describe (1) the relationship between oxygen content and volatility, (2) the probability of fragmentation and (3) the amount of oxygen added per reaction. The time-evolution and absolute value of the simulated SOA mass depends sensitively on all tunable parameters. Of the tunable parameters, the mean $\mathrm{O}: \mathrm{C}$ is most sensitive to the oxygen/volatility relationship, exhibiting only a weak dependence on the other relationships. The model mean particle $\mathrm{O}: \mathrm{C}$ produced from a given compound is primarily controlled by the number of carbon atoms comprising the SOA precursor, with some sensitivity to the specified oxygen/volatility relationship. The model is tested against laboratory measurements of time-dependent SOA formation from the photooxidation of $\alpha$-pinene and $n$-pentadecane and performs well (after tuning). The model can also accurately simulate the carbon-number dependence of aerosol yields previously observed for oxidation of straight-chain alkanes. This model may provide a generalized framework for the interpretation of laboratory SOA formation experiments in which explicit consideration of multiple-generations of products is required, which is true for all photo-oxidation experiments.
\end{abstract}

\section{Introduction}

Atmospheric aerosol particles play a key role in the Earth's climate system by absorbing and scattering solar radiation and influencing properties of clouds (IPCC, 2007). The influence of aerosols on climate depends on their composition, yet much remains unknown with respect to formation, chemical evolution and removal pathways, especially when considering organic aerosols (OA) (Jacobson et al., 2000; Seinfeld and Pankow, 2003; Kanakidou et al., 2005). A primary challenge in developing comprehensive quantitative understanding of organic aerosols derives from their high chemical complexity, which results from there being a myriad of sources. Individual particles can be composed of numerous compounds, including organics, inorganics and soot; OA has both primary (i.e. direct emission, POA) and secondary (i.e. gas-to-particle conversion, SOA) sources and may be comprised of hundreds of different compounds (Kanakidou et al., 2005).

In the context of traditional equilibrium partitioning theory, the extent to which an organic compound partitions to the particle phase depends on the temperature-dependent volatility (Pankow, 1994) which varies over orders of magnitude for compounds in aerosols (e.g. Cappa et al., 2007, 2008). Quantitative understanding of the partitioning of organics between the gas and particle phase has been thought to be essential for accurately predicting the spatial and temporal distribution of $\mathrm{OA}$ in the atmosphere. However, typical models of $\mathrm{OA}$ formation in the atmosphere have tended to predict significantly less OA than is commonly observed (de Gouw et al., 2005; Heald et al., 2005; Johnson et al., 2006; Volkamer et al., 2006; Matsui et al., 2009). Recent updates 
to models of OA to include e.g. semi-volatile primary OA (Robinson et al., 2007) or new estimates of aerosol yields for aromatics (Ng et al., 2007b) have led to somewhat better model/measurement agreement in terms of the total OA mass (Dzepina et al., 2009). However, the physical properties of the model OA are at times inconsistent with observations of OA volatility, with the model aerosol often being too volatile (Dzepina et al., 2009, 2011) or with too low an oxygen-to-carbon (O:C) ratio (Hodzic et al., 2010; Dzepina et al., 2011). When models do appear to give reasonable apparent volatilities they tend to use unrealistic input parameters (e.g. enthalpies of vaporization; Jathar et al., 2011). Models that appear to give reasonable values for O : C typically assume very large increases in mass upon reaction of a volatile organic compound (VOC) with $\mathrm{OH}$, e.g. $40 \%$ per reaction, all of which is assumed to be oxygen (Grieshop et al., 2009; Hodzic et al., 2010; Dzepina et al., 2011). This suggests that, although there may be better agreement with observations of OA mass using updated models, the agreement may be fortuitous. This is problematic since model aerosol that is too volatile will respond to perturbations (such as dilution or temperature fluctuations) in unrealistic ways, which could lead to incorrect estimates of air quality and climate effects of particles.

In this study, the development of a kinetic model of gasphase hydrocarbon oxidation coupled to secondary OA formation via gas-particle equilibrium partitioning is described. The model simulates both SOA mass and the bulk aerosol $\mathrm{O}: \mathrm{C}$ atomic ratio. The model represents a new framework in which laboratory observations of OA growth can be considered and parameterized, potentially for use within regional and global models. In Sect. 2, a description of the modeling framework is given. In Sect. 3.1, the model is run to explore the influence of specific tunable parameters on the general model results and to develop semi-quantitative understanding of SOA formation from gas-phase processing. In Sect. 3.2, the utility of the model framework is demonstrated by explicitly fitting the model to laboratory measurements of SOA formation. In Sect. 3.3, further extensions of the model are considered.

\section{Model description}

The statistical oxidation model (SOM) developed here frames the oxidation chemistry of a hydrocarbon as a trajectory through a multi-generational space defined by the number of carbon and oxygen atoms comprising the SOA precursor and all possible product molecules. Our model is, in some ways, a hybrid of the conceptual carbon-oxidation state framework of Kroll et al. (2011), the 2-D volatility basis set (VBS) model of Donahue and co-workers (Jimenez et al., 2009; Donahue et al., 2011) and the carbon numberpolarity grid of Pankow and Barsanti (2009), all placed into an explicit kinetic framework. It is, in essence, a simplified and condensed version of the explicit gas-phase photochemistry models that have been developed (e.g. Aumont et al., 2005). The SOM shares some similarities with kinetic ("ageing") implementations of the carbon number-polarity grid (Barsanti et al., 2011) and of the 1D VBS (e.g. Robinson et al., 2007; Lane et al., 2008). For example, the kinetic VBS allows for reaction of product species with $\mathrm{OH}$ and the continued formation of lower volatility (multi-generation) material from these reactions. The SOM is, nonetheless, unique in the specification of parameters that describe the oxidation process and SOA formation through multiple generations of oxidation while accounting explicitly for functionalization and fragmentation of all product species.

Within the SOM, functionalization reactions produce molecules with the same number of carbon atoms $\left(N_{\mathrm{C}}\right)$ as the parent compound but a larger number of oxygenated functional groups (Sect. 2.3). Fragmentation reactions lead to $\mathrm{C}-\mathrm{C}$ bond scission and the formation of two smaller molecules (Sect. 2.4). In the current model framework, the distribution of compounds between the gas and particle phase is treated through equilibrium partitioning theory (Pankow, 1994) (Sect. 2.2). In the base case model only gas-phase reactions are allowed (Sect. 2.1), although heterogeneous reactions are also considered (Sect. 2.5). Within the model, all compounds are allowed to react with $\mathrm{OH}$ radicals, with the exception of $\mathrm{CO}_{2}$, which represents the end point of oxidation. In other words, every compound represents a species that is both formed and consumed by $\mathrm{OH}$, with the exception of the initial SOA precursor. (Although all products could therefore be considered "SOA precursors", we restrict this term to mean the initial, unreacted hydrocarbon.)

Neither hydrogen atoms nor functional groups are explicitly considered in the SOM; instead average molecular properties are specified for the "species" that populate a matrix of all possible $N_{\mathrm{C}}$ and $N_{\mathrm{O}}$ combinations (up to a limit of $N_{\mathrm{O}} / N_{\mathrm{C}}=2$ ). Each cell in the matrix effectively represents an average of some number of e.g. ketones, alcohols, peroxides. The relationship between "structure" (i.e. the number of carbon and oxygen atoms) and a given property (e.g. volatility or oxygen addition) are tunable parameters in the model. The specific tunable parameters in our model are as follows:

1. The distribution of oxygen atoms added per reaction.

2. The decrease in vapor pressure (volatility) per oxygen added.

3. The probability of a given reaction producing fragments.

These parameters govern the trajectory that the oxidation takes through the carbon/oxygen space and can be envisioned as unique to a given reaction (e.g. dodecane $+\mathrm{OH}$ ) or, perhaps, a class of reactions (e.g. straight-chain alkanes $+\mathrm{OH}$ ). Together these parameters will determine the absolute value of and temporal variation in gas and particle phase oxidation 
products, ultimately determining the aerosol yield, the average $\mathrm{O}: \mathrm{C}$ ratio and the average volatility of the $\mathrm{OA}$. Values for these parameters for a given reaction can be explicitly determined by fitting the SOM to laboratory SOA formation experiments, although general insights into SOA formation can be obtained by varying the parameters within physically realistic ranges. In a sense, these tunable parameters are related to the specification of product yields within the static volatility basis-set (Donahue et al., 2006) or product yields and volatilities within the "two-product model" (Odum et al., 1996). However, the SOM parameters are explicitly formulated to account for the kinetics of oxidation and the formation of multiple-generations of gas and particle-phase reaction products throughout the aerosol formation process. The SOM shares some similarities with multi-generational oxidation schemes as implemented within the 1D VBS framework (Robinson et al., 2007) in that the kinetic VBS similarly requires specification of a variety of parameters (e.g. volatility decrease per reaction) that control the model evolution. A unique aspect of the SOM is that the atomic composition of individual "molecules" is determined (i.e. $N_{\mathrm{C}}$ and $N_{\mathrm{O}}$ ), and the properties of these species are specified based on their "structure" to determine the evolution of the gas/particle system throughout a reaction. Henceforth when we refer to "structure" in the context of the SOM we specifically mean a species that has a particular $N_{\mathrm{C}}$ and $N_{\mathrm{O}}$ and are not implying any particular arrangement of atoms. Again, we emphasize that the SOM provides an average representation of the oxidation trajectory taken by a given parent hydrocarbon through the $N_{\mathrm{C}} / N_{\mathrm{O}}$ space. Actual structural differences between precursor species or their oxidation products are captured within the tunable parameters of the model; specific values for these parameters can be determined by fitting to chamber observations of time-dependent SOA formation.

In photo-oxidation experiments the oxidation products themselves are reactive towards $\mathrm{OH}$. As a result, products with relatively large numbers of oxygen atoms always have some probability of being formed, even early on in the reaction. This is simply a consequence of statistical oxidation in a well-mixed system. For example, for the case where all molecules react with $\mathrm{OH}$ with the same rate coefficient $\left(k_{\mathrm{OH}}\right)$, the distribution of oxidation products at any point in the reaction can be described as a simple Poisson distribution, as recently shown by Wilson et al. (2012). Note that "generation" is equal to the number of times that a molecule has reacted, starting from the initial SOA precursor. Further, because more than 1 oxygen-containing functional group can be added per reaction, the number of oxygens per molecule is not necessarily equal to the number of "generations" of oxidation. Understanding of the evolution of these later generation products is challenging, although chemically explicit models such as the GECKO-A (Camredon et al., 2007; LeeTaylor et al., 2011; Valorso et al., 2011) have provided useful insights.
For a single SOA precursor, it is useful to follow the evolution of the system with respect to loss of the SOA precursor, which can be quantified by the number of "oxidation lifetimes", defined as $N_{\tau}=t / \tau_{\mathrm{OH}}$ where $t$ is the elapsed reaction time and $\tau_{\mathrm{OH}}$ is the oxidation lifetime $\left(=1 / k_{\mathrm{OH}}[\mathrm{OH}]\right.$, where $[\mathrm{OH}]$ is the concentration of $\mathrm{OH}$ radicals). The distribution of product species formed from any SOA precursor is continuously evolving throughout a reaction in both the gas and particle phases. In the SOM, these time-dependent distributions are explicitly computed as the reaction proceeds. The exact form and kinetic evolution of these distributions depend on how the model is parameterized, as described above and in detail in sections below.

For example, the distribution of gas and particle phase species formed in a generic photooxidation reaction is shown in Fig. 1. For illustrative purposes, fragmentation is neglected and it is assumed that only 1 oxygen functional group is added per reaction. Thus the number of oxygens $\left(N_{\mathrm{O}}\right)$ is equal to the generation number, $n$. Before reaction, there is only gas-phase material with the number of carbon atoms $\left(N_{\mathrm{C}}\right)$ equal to the SOA precursor and $N_{\mathrm{O}}=0$. Upon reaction, a small amount of $1 \mathrm{st}, 2 \mathrm{nd}, \ldots, n$-th generation products are produced almost instantaneously, even after little of the SOA precursor hydrocarbon has been consumed (i.e. at $N_{\tau} \ll 1$ ). Since higher- $n$ generations have lower volatility (i.e. more oxygen for the same $N_{\mathrm{C}}$ ), the particle phase distribution at this point is dominated by these compounds, which reside at the tail-end of the product distribution, even though they make up a negligible amount of the total mass. As the reaction continues, the total abundance of these later-generation products increases, producing a broader distribution of product generations that evolve towards larger average $n$ with increasing oxidation. As the total abundance of any given $n$-th generation product increases, the amount that partitions to the particle phase will also increase, thus accelerating the total amount of OA that is formed because the extent to which a given compound partitions to the particle phase increases with the total amount of OA (Pankow, 1994).

Figure 1 reveals how the distribution of specific species (generations) continuously evolve during photooxidation due to reactions of both the SOA precursor and product species, which indicates that the yield of a given species is not static. This result is not surprising, since all products are assumed to react with $\mathrm{OH}$, but this aspect is often not accounted for in the fitting of traditional aerosol yield experiments where it is implicitly assumed (although not always stated) that product distributions are static. Figure 1 illustrates the continuous nature of photooxidation as well as the importance of considering the formation and evolution of product distributions in both the gas and particle phases. We note that chemically explicit kinetic models of SOA formation inherently account for the continuous evolution of product distributions throughout a reaction. 


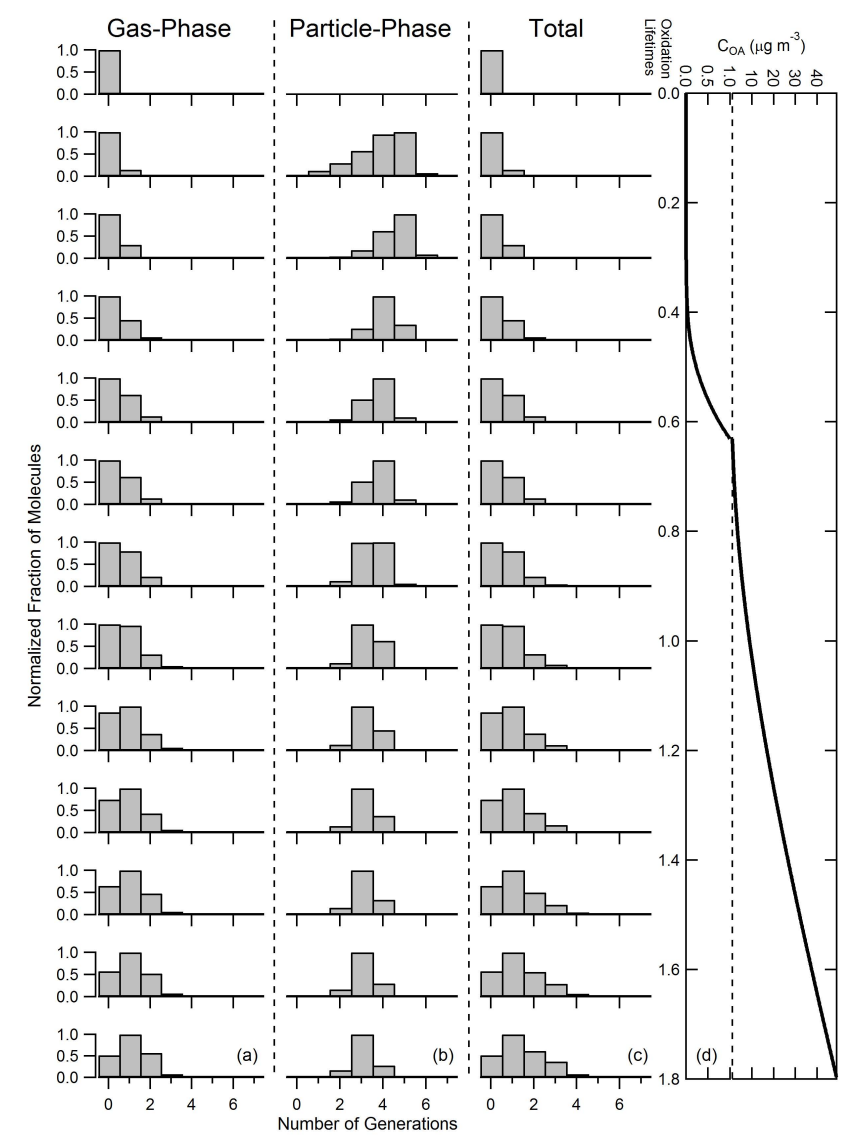

Fig. 1. The time-evolution of gas (a), particle (b) and total (c) distributions upon reaction of a generic hydrocarbon with $\mathrm{OH}$, normalized to the maximum abundance at each point in the simulation. For reference, the evolution of the total OA mass is shown in (d) as a function of the number of oxidation lifetimes (note the split $y$-axis and change in scale). Note the continuous evolution of the compound distributions.

The model developed herein takes into account the timeevolution of the product distributions, which would seemingly suggest greater complexity of the SOM compared with traditional 2-product or more recent static VBS parameterizations of aerosol yields. However, the number of tunable parameters is limited (to two constants and 1 array, or 6 total parameters), and thus only slightly larger than these other formulations (4 parameters for a 2-product model (Odum et al., 1996) or, typically, 4 parameters for the static VBS model (Donahue et al., 2006)). One of the strengths of the SOM approach is that the derived parameters explicitly include ageing as part of the fundamental formulation. The details of how species move through the carbon-oxygen matrix for a specific photooxidation reaction will depend explicitly on how these tunable parameters are specified. A key feature of the SOM is that it is possible to do this in a reasonably physically realistic manner (since the parameters have, in principle, physically interpretable meaning) and to test the valid- ity of any parameterization against smog chamber measurements of SOA yield and composition. Of course, any such interpretations of the meaning of the derived SOM parameters must recognize that they are constrained by the limitations of the SOM framework. Below we outline how various parameters are assigned to the individual species within the $N_{\mathrm{C}} / N_{\mathrm{O}}$ distribution.

\subsection{Parameterization of compound reactivity}

All molecules in the carbon/oxygen matrix are assumed to be reactive with $\mathrm{OH}$. Each species in the carbon/oxygen matrix has a unique rate coefficient $\left(k_{\mathrm{OH}}\right)$ that depends on the length of the carbon backbone, the number of oxygen atoms and the nature of the functional groups added. The rate coefficients in the SOM are computed using a modified version of typical structure-reactivity relationships (Kwok and Atkinson, 1995), as detailed in the Supplement. The need for a modified structure-reactivity relationship arises in part because the SOM does not explicitly keep track of the types of functional groups formed, and thus cannot use parameters unique to the addition of a ketone or alcohol, for example. Nor does the SOM account for structural differences of a given $N_{\mathrm{C}} / N_{\mathrm{O}}$ pair. Thus, the derived relationship is not truly a "structure"reactivity relationship, and therefore is referred to as the SOM-reactivity relationship. A fundamental assumption underlying the SOM-reactivity relationship is that equal numbers of ketones and alcohol groups are added, on average, upon oxidation. Additionally, the base-case SOM-reactivity relationship is based on the reactivity of straight-chain alkanes.

In principle, the SOM-reactivity relationship developed in the Supplement can be altered to account for any specific starting compound where, for example, the presence of double bonds may make the reactivity of the SOA precursor towards $\mathrm{OH}$ much larger than that of the products. Reactions of $\mathrm{OH}$ with alkenes that have a single double bond can be represented by uniquely specifying the rate coefficient of the SOA precursor and then using the SOM-reactivity relationship to determine the reactivity of the later generation products. Alternatively, reactions of alkenes with $\mathrm{O}_{3}$ can be represented by setting the rate coefficients of the products to zero (assuming only 1 double bond is present) because the products are essentially unreactive towards $\mathrm{O}_{3}$. The reactivity of species with multiple double bonds, such as sesquiterpenes or isoprene, is not currently well-captured by the SOM framework. Although the SOM-reactivity relationship does not explicitly account for the influence of molecular structure (e.g. straightchain vs. branched vs. cyclic compounds), structural differences can be accounted for, to first order, by multiplying the entire rate coefficient matrix by an appropriate constant or by allowing the parent species to have a reactivity that differs from the product species. 


\subsection{Gas-particle partitioning and compound volatility}

At each time step in the model, the system is assumed to achieve gas-particle equilibrium, which can be described through partitioning theory (Pankow, 1994). The extent of partitioning for a given compound is governed by the saturation concentration, $C^{*}$ :

$C_{i}^{*}=\frac{\mathrm{MW}_{i} p_{\mathrm{sat}, i} \zeta_{i}}{R T}$

where $\mathrm{MW}_{i}$ is the molecular weight $\left(\mathrm{g} \mathrm{mol}^{-1}\right), R$ is the ideal gas constant $\left(8.314 \mathrm{~J} \mathrm{~mol}^{-1} \mathrm{~K}^{-1}\right), T$ is the temperature (K), $\zeta_{i}$ is the activity coefficient in the OA phase and $p_{\text {sat }, i}$ is the (sub-cooled liquid) saturation vapor pressure $(\mathrm{Pa})$ of compound $i$ (which may also represent a class of compounds). We assume $\zeta_{i}$ is unity, and thus $C^{*}$ can best be thought of as an effective saturation concentration, although we note that the model works independent of this assumption. In the general model formulation, hydrogen atoms are accounted for in the $\mathrm{MW}_{i}$ by using saturated hydrocarbons when $N_{\mathrm{O}}=0$ and assuming the number of hydrogen atoms decreases by 1 for each oxygen added; because of the much larger MW of carbon and oxygen atoms, this assumption has a negligible influence on the model results. In addition to $C^{*}$, the specific distribution of compounds between the particle and gasphases depends on both the gas and particle phase abundance of that compound $\left(C_{i, \text { tot }}=C_{i, \text { gas }}+C_{i \text {,aer }}\right.$, gas + aerosol $)$ and the total organic aerosol concentration $\left(C_{\mathrm{OA}}\right)$ according to (Pankow, 1994):

$C_{\mathrm{OA}}=\sum_{i} C_{i, \text { tot }}\left(1+\frac{C_{i}^{*}}{C_{\mathrm{OA}}}\right)^{-1}$

It is well known that $p_{\text {sat }}$ (and thus $C^{*}$ ) depends primarily on the length of the carbon backbone and the number and type of functional groups, and secondarily on specific molecular structure (Pankow and Asher, 2008). The addition of a ketone to a hydrocarbon backbone leads to a decrease in vapor pressure by a factor of $\sim 10-20$, an alcohol by a factor of $\sim 160$, and with the addition of a carboxylic acid group simply the product of these two. Previous work shows that the addition of all of these functional group types to SOA-forming hydrocarbons is possible, with some indication that, on average, equal numbers of ketones and alcohols are added (Heald et al., 2010), or that alcohol and carboxylic acid moieties are more prevalent than ketones (Ng et al., 2011; Russell et al., 2011), although hydroperoxides (low- $\mathrm{NO}_{\mathrm{x}}$ conditions) or organic nitrates (high- $\mathrm{NO}_{\mathrm{x}}$ conditions) may also contribute.

In the SOM, only the number of carbon and oxygen atoms is considered, rather than specific functional groups. This is because the framework of our model is a carbon/oxygen grid, so the change in vapor pressure is considered on a per oxygen basis rather than on a per functional group basis. Since the addition of a single oxygen-containing moiety decreases the vapor pressure by orders of magnitude, we will use the logarithmic change in vapor pressure, termed $\triangle \mathrm{LVP}$, throughout.
For example, it follows that $\Delta \mathrm{LVP} \sim 1$ corresponds to the addition of one oxygen atom as a ketone group (a factor of 10 decrease), while $\Delta \mathrm{LVP} \sim 2.23$ corresponds to an alcohol group (a factor of 160 decrease) (Pankow and Asher, 2008).

The oxygen/volatility relationship (i.e. $\triangle$ LVP) is a tunable parameter in the model that can, in principle, vary over the range bounded by the addition of functional groups of various types. In addition to the alcohols and ketones mentioned above, hydroperoxides would have a $\triangle \mathrm{LVP} \sim 1.24$ while nitrate groups would have a $\triangle \mathrm{LVP} \sim 0.74$, both on a per-oxygen basis (Pankow and Asher, 2008). Further, alcohols exhibit a range of $\Delta \mathrm{LVP}$ (up to $\sim 2.75$, typically $\sim 2.2$ ), depending on whether they are primary, secondary or tertiary. In the SOM, the base volatility of the carbon backbone is calculated as $\log _{10} C^{*}=-0.0337 \mathrm{MW}_{\mathrm{HC}}+11.56(\mathrm{de}-$ termined from data in Lide and Kehiaian, 1994), where $\mathrm{MW}_{\mathrm{HC}}$ is the molecular weight of the SOA precursor carbon backbone, including hydrogen atoms. Thus the overall $C^{*}$ for a given "molecule" in the model is $\log _{10} C^{*}=$ $-0.0337 \mathrm{MW}_{\mathrm{HC}}+11.56-\left(N_{\mathrm{O}} \times \Delta \mathrm{LVP}\right)$.

It is assumed that $\Delta \mathrm{LVP}$ is constant across the $N_{\mathrm{C}} / N_{\mathrm{O}}$ matrix and does not vary with time; this simplification must be kept in mind when interpreting the $\Delta$ LVP parameter. In principle, $\triangle \mathrm{LVP}$ could be given a functional form that varies with, for example, the $\mathrm{O}: \mathrm{C}$ ratio for a given $N_{\mathrm{C}}$ compound or could be treated as a distribution. Such additional complexity may certainly be justified, especially for compounds that contain rings or double bonds, but even for saturated hydrocarbons. Some observations of ambient organic aerosol (cf. Fig. 3c in Heald et al., 2010) and of organic aerosol in laboratory experiments where heterogeneous oxidation is either exclusively considered (Kroll et al., 2009) or competes efficiently with gas-phase reactions (Lambe et al., 2012) indicate curvature in the van Krevelen diagram, which is a graph of $\mathrm{H}: \mathrm{C}$ vs. $\mathrm{O}: \mathrm{C}$; curvature suggests that the nature of the average functional group being added is changing as the mean extent of oxidation changes. However, some other observations of $\mathrm{H}: \mathrm{C}$ vs. O : $\mathrm{C}$ for ambient SOA from individual field campaigns show negligible curvature (cf. Fig. 3a and $3 b$ in Heald et al., 2010), as do some individual laboratory experiments, albeit over a limited range of $\mathrm{O}: \mathrm{C}$ values (Chhabra et al., 2011). In the current SOM we have selected to use a constant $\triangle \mathrm{LVP}$; later (in Sect. 3.2), we will show that the use of a constant $\triangle$ LVP allows for accurate simulation of the evolution of SOA mass during laboratory formation experiments, suggesting that this simplification is reasonable. Additional comparisons between the SOM and laboratory chamber data in the future will help to establish the extent to which the assumption of constant $\triangle \mathrm{LVP}$ is generally sufficient.

There is some evidence that SOA is not fully describable through equilibrium partitioning theory on short timescales (minutes to a few hours), likely as a result of condensed phase reactions that alter the particle composition (e.g. Virtanen et al., 2010; Cappa and Wilson, 2011; Koop et al., 2011; Vaden et al., 2011). The SOM does not account for such 
complications, as it is implicitly assumed that gas-particle equilibrium is achieved at each model timestep $(\sim 1 \mathrm{~min})$. Consideration of (non-heterogeneous) condensed-phase reactions within the SOM framework will be the subject of future work. Additionally, in chamber experiments losses of particles and gases to the chamber walls can influence the gas-particle partitioning (e.g. Hildebrandt et al., 2009; Loza et al., 2010; Matsunaga and Ziemann, 2010). Currently, the SOM does not explicitly account for wall losses. As such, when the SOM is fit to chamber data, the derived fit parameters inherently include the influence of walls on the gasparticle partitioning as well as the influence of condensed phase reactions. Finally, the assumption of gas-particle equilibrium does not account for the dynamics of mass transfer, which may be important when particle surface area is limited (Parikh et al., 2011).

\subsection{Functionalization}

Functionalization reactions are considered through the addition of oxygen upon reaction with $\mathrm{OH}$ in the presence of $\mathrm{O}_{2}$. The number of oxygen atoms added per reaction is a tunable parameter within the model. It is assumed that the $\mathrm{OH}$ reaction leads to a distribution of functionalized products in which 1,2, 3 or 4 oxygens can be added as a result of the single $\mathrm{OH}$ attack. The probability of adding any given number of oxygen atoms is specified, with the total probability of oxygen addition summing to unity (i.e. reactions always lead to oxygen addition). For example, if it is assumed that a single $\mathrm{OH}$ reaction leads to a distribution of products where $50 \%$ have added 1 oxygen, $50 \% 2$ oxygens and no contributions from 3 or 4 oxygens, the functionalization probability array (or operator) would have the form $P_{\text {func }}=\left[P_{\text {func }, 1}\right.$, $\left.P_{\text {func, } 2}, P_{\text {func, } 3}, P_{\text {func, } 4}\right]=[0.5,0.5,0.0,0.0]$, where the numbers in brackets correspond to the probability of addition of $1,2,3$ or 4 oxygen atoms, respectively. It is straight-forward to translate the distribution of generations shown in Fig. 1 to number of oxygens if it is assumed that only $n$-oxygens are added per reaction (and no fragmentation), but if a distribution of oxygens is added per reaction, then generation number and oxygen content cannot be shown in such a simple manner. As with the $\triangle$ LVP parameter, it is assumed that the functionalization operator for a given SOA precursor is constant across the entire $N_{\mathrm{C}} / N_{\mathrm{O}}$ matrix and does not evolve in time. Given the complexity of the chemical pathways associated with hydrocarbon oxidation, $P_{\text {func }}$ very likely varies with composition, especially if the parent hydrocarbon contains a ring or a double bond, but also even for alkanes; we find that use of a constant $P_{\text {func }}$ allows for accurate fitting and simulation of the time-evolution of SOA growth in chamber experiments (see Sect. 3.2). Interpretations of the $P_{\text {func }}$ array in terms of physical properties must keep this assumption in mind. In the future, it may be desirable to allow for a $P_{\text {func }}$ array that varies with composition, for example by allowing $P_{\text {func }}$ for reaction of the parent compound to differ from $P_{\text {func }}$ for subsequent reactions of product species. This will be assessed through further comparison of the SOM to laboratory chamber data. (Note that although the discussion above focuses on reactions of hydrocarbons with $\mathrm{OH}$, the SOM can be formulated for use with $\mathrm{O}_{3}$ reactions with alkenes that contain 1 double bond through modification of the rate coefficient matrix, as discussed in Sect. 2.1.)

Again, the type of functional group added (e.g. ketone vs. alcohol) is not explicitly tracked in the SOM. However, once the oxygen/volatility relationship is specified, one can in principle infer the average number of hydrogen atoms in any grid cell in the carbon/oxygen matrix. Recently, there has been interest in understanding how OA evolves in the space defined by the $\mathrm{H}: \mathrm{C}$ and $\mathrm{O}: \mathrm{C}$ ratio, i.e. a van Krevelen plot (e.g. Heald et al., 2010); any given point in this space can be characterized by the mean oxidation state, defined as $\mathrm{OS}_{\mathrm{C}}=2 \mathrm{O}: \mathrm{C}-\mathrm{H}: \mathrm{C}$ (Kroll et al., 2011). $\mathrm{OS}_{\mathrm{C}}$ is implicitly a part of the SOM because, by specifying a value for $\triangle \mathrm{LVP}$ the evolution of the hydrogen content of the system is, in principle, effectively constrained. The addition of an alcohol functional group increases $\mathrm{O}: \mathrm{C}$ but leaves $\mathrm{H}: \mathrm{C}$ unchanged, whereas the addition of a ketone decreases $\mathrm{H}: \mathrm{C}$ and increases $\mathrm{O}: \mathrm{C}$. If the $\triangle \mathrm{LVP}$ is viewed simply as a linear combination of ketone and alcohol group addition, then the evolution of the hydrogen content (and thus of $\mathrm{OS}_{\mathrm{C}}$ ) can be determined. This, of course, ignores contributions of hydroperoxides or other functional groups and of condensed phase reactions that might alter the functional group distribution but can provide a first order constraint on the mean $\mathrm{OA} \mathrm{OS}$. For example, if $\triangle \mathrm{LVP}=1.6$, this corresponds approximately to equal addition of ketones and alcohols. So, for the addition of 1 oxygen to an alkane SOA precursor, the functionalized product will have lost, on average, 1 hydrogen atom. In this framework, by specifying $\triangle \mathrm{LVP}$, the slope in a Van Krevelen plot is essentially being specified a priori; if $\Delta \mathrm{LVP}=1$ then the Van Krevelen slope is -2 , whereas if $\triangle \mathrm{LVP}=2.2$ the van Krevelen slope is 0. Alternatively, if measurements of both $\mathrm{H}: \mathrm{C}$ and $\mathrm{O}: \mathrm{C}$ are available, one can adjust the model parameters to try and match the observed values. However, it must be noted that any interpretation of the meaning of $\triangle \mathrm{LVP}$ in terms of the type of functional groups added is restricted, in part, by the lack of condensed phase reactions in the SOM and by limitations imposed by our assumptions regarding the form of the reaction rate coefficient matrix and the constant nature of $\triangle \mathrm{LVP}$ and the functionalization operator.

\subsection{Fragmentation}

There is a probability that reaction with $\mathrm{OH}$ will lead to C$\mathrm{C}$ bond scission, fragmenting the parent molecule into two, smaller molecules. Because fragmentation is generally considered to be more probable when $\mathrm{OH}$ attack occurs near an already existing oxygenated functional group, the probability of fragmentation of a given species upon reaction is 
parameterized in the SOM as:

$P_{\text {frag }}($ per reaction $)=c_{\text {frag }} N_{\mathrm{O}}$

where $c_{\text {frag }}$ is a tunable parameter. The linear dependence on $N_{\mathrm{O}}$ (Eq. 3) prevents small molecules from excessively fragmenting upon the addition of the first oxygen. Other functional forms for $P_{\text {frag }}$ are possible, such as a more general form of that proposed by Jimenez et al. (2009):

$P_{\text {frag }}($ per reaction $)=\left(\frac{N_{\mathrm{O}}}{N_{\mathrm{C}}}\right)^{m_{\mathrm{frag}}}$

where $m_{\text {frag }}$ is a tunable parameter. As will be shown in Sect. 3.2, both functional forms can provide good agreement with observations, after tuning. Determination of the preferred functional form for $P_{\text {frag }}$ is the subject of future work.

Upon fragmentation, the distribution of product species amongst all possible choices is computed assuming a random probability for the location of the C-C bond scission and thus the resulting size of the scission product. The corresponding species is then deduced from what atoms remain so as to achieve mass balance (in terms of the number of carbon and oxygen atoms). This method rapidly distributes mass amongst the entire carbon/oxygen matrix. In actuality, fragmentation is most likely to occur adjacent to an oxygenated functional group or at a tertiary carbon, but since the SOM keeps track only of numbers of oxygen and carbon atoms and not structure, assuming random fragmentation is appropriate. Fragmentation necessarily requires the addition of at least one oxygen atom to both fragments (Kroll and Seinfeld, 2008). Therefore, we assume that the probability of obtaining a species with zero oxygen atoms upon fragmentation is zero. To account for the additional oxygen addition that accompanies a fragmentation reaction (as opposed to a non-fragmenting functionalization reaction), we assume that one additional oxygen atom is added to one of the fragments. This may underestimate oxygen addition to the fragmented molecules if more than one oxygen is added from the fragmentation pathway. For example, if the $\mathrm{C}_{12} \mathrm{O}_{2}$ species reacts to add 1 oxygen (via functionalization) but also fragments with half the carbon going to each fragment, the following resulting species pairs are possible: $\mathrm{C}_{6} \mathrm{O}_{3}+\mathrm{C}_{6} \mathrm{O}_{1}$ and $\mathrm{C}_{6} \mathrm{O}_{2}+$ $\mathrm{C}_{6} \mathrm{O}_{2}$. As with the addition of distributions of oxygens per reaction, fragmentation further complicates the relationship between generation number and oxygen content, and requires specific consideration of the distribution of molecules in a multi-dimensional space defined by $N_{\mathrm{C}}, N_{\mathrm{O}}$ and abundance, with properties of every species (i.e. $N_{\mathrm{C}} / N_{\mathrm{O}}$ pair) explicitly specified according to the relationships defined in the previous sections.

\subsection{Heterogeneous chemistry}

Condensed phase molecules can react with gas-phase molecules (i.e. $\mathrm{OH})$ via heterogeneous reactions. For OA, various studies have shown that heterogeneous oxidation by $\mathrm{OH}$ radicals leads to the addition of oxygen to the particle (via functionalization) but can also lead to net loss of particle mass (via fragmentation) (George et al., 2007; Kroll et al., 2009; Smith et al., 2009; Wong et al., 2011). The heterogeneous reaction rate of a given species in a single particle depends on the collision rate of $\mathrm{OH}$ with the particles, the relative abundance of that species and the reactive uptake coefficient, and can be written for species " $\mathrm{R}$ " as:

$\frac{\mathrm{d}[R]}{\mathrm{d} t}=\gamma_{\mathrm{OH}} \cdot J_{\mathrm{coll}} \cdot \mathrm{SA} \cdot f \cdot N_{\mathrm{p}}=\gamma_{\mathrm{OH}} \cdot \bar{c} \cdot[\mathrm{OH}] \cdot \pi D_{\mathrm{p}}^{2} \cdot f \cdot N_{\mathrm{p}}$

where $\gamma_{\mathrm{OH}}$ is the $\mathrm{OH}$ reactive uptake coefficient, $J_{\text {coll }}$ is the collision rate of $\mathrm{OH}$ molecules with the particle and is equal to $[\mathrm{OH}] \cdot \bar{c} / 4, \bar{c}$ is the mean speed of gas-phase $\mathrm{OH}, \mathrm{SA}$ is the (spherical) particle surface area, $D_{\mathrm{p}}$ is the particle surfaceweighted diameter, $f$ is the fraction of the particle that is the particular species of interest and $N_{\mathrm{p}}$ is the particle number concentration. There are some measurements of $\gamma_{\mathrm{OH}}$ available, and these suggest that $\gamma_{\mathrm{OH}}$ can vary from $\sim 0.3$ to 3 (Bertram et al., 2001; Hearn and Smith, 2006; George et al., 2007; Hearn et al., 2007; Lambe et al., 2007, 2009; McNeill et al., 2008; Che et al., 2009; Smith et al., 2009; Kessler et al., 2010), with values $>1$ indicating a role for secondary (chain-propagating) chemistry in the condensed phase (Liu et al., 2011). Smith et al. (2009) demonstrated that for heterogeneous $\mathrm{OH}$ oxidation of a long-chain saturated hydrocarbon $\left(\mathrm{C}_{30}\right)$, one oxygen atom is added on average per $\mathrm{OH}$ reaction. We therefore assume that, in general, heterogeneous reactions with $\mathrm{OH}$ radicals add only 1 oxygen per reaction (i.e. $\left.P_{\text {func }}=[1,0,0,0]\right)$ when functionalization occurs without fragmentation; this condition can be relaxed as experiments provide new insights. To account for fragmentation, we assume that the $P_{\text {frag }}$ parameterization described above for gas-phase reactions equally applies to condensed phase reactions. Fragmentation can lead to loss of particle mass because the increased volatility of the fragments, relative to the parent species, can lead to evaporation. We do not account for possible oligomerization reactions that result from heterogeneous processing. Particle size influences the heterogeneous oxidation rate. In the SOM, the particle number concentration can be specified as a model input, and from this the evolution of the (spherical) particle size can be followed; it is assumed that the particle size distribution is monodisperse. This model of heterogeneous $\mathrm{OA}+\mathrm{OH}$ chemistry allows for assessment of the approximate influence/importance of heterogeneous reactions relative to purely gas-phase processing. In this study, heterogeneous chemistry will be considered as an additional model aspect and is not implemented in the base case model formulation. 


\section{Results and discussion}

\subsection{Oxidation trajectories through the carbon/oxygen space}

In this section general results from the SOM are discussed in terms of how variations in the tunable parameters influence the time-evolution of the model SOA mass concentration and $\mathrm{O}: \mathrm{C}$ atomic ratio.

\subsubsection{No fragmentation}

First, the case where no fragmentation $\left(c_{\text {frag }}=0\right)$ occurs is considered. Without fragmenation, reactions of the gas-phase SOA precursor with $\mathrm{OH}$ will lead only to the production of products with the same carbon number $\left(N_{\mathrm{C}}\right)$ but with increasing oxygen content, as illustrated in Fig. 1. Starting from a single compound (e.g. dodecane), the rate at which the overall system (gas + particle) adds oxygen is controlled by the functionalization array, $P_{\text {func }}$. However, the rate at which the aerosol becomes oxygenated will additionally be determined by the instantaneous aerosol mass loading, the specific compound volatilities and the assumed $\triangle$ LVP. As oxidation proceeds, increasing amounts of lower volatility (higher $N_{\mathrm{O}}$ ) products in the distribution will be produced.

Products with lower volatility partition more strongly to the particle-phase than higher volatility compounds. Aerosol composition depends both on these volatility differences and the absolute abundance of each compound. The evolution of the particle composition depends on the interplay of these two factors, along with the variation in the total $C_{\mathrm{OA}}$. Without fragmentation, the ability to add oxygen to the particle phase is limited by the decreasing volatility of the products upon oxygen addition. Assuming equilibrium partitioning theory applies, there is an effective upper limit to the addition of oxygen because, once a compound becomes of sufficiently low volatility (i.e. $>99 \%$ partitioned to the particle phase), the rate of gas-phase oxidation becomes negligible and further oxygen addition becomes slow. Within the SOM framework, this limit is strongly determined by the combination of the SOA gas-phase precursor $N_{\mathrm{C}}$ and the assumed $\triangle \mathrm{LVP}$ per reaction when fragmentation is excluded.

The dependence of the particle-phase $\mathrm{O}: \mathrm{C}$ and aerosol yield on $N_{\mathrm{C}}$ have been explored by performing calculations where it was assumed that $\triangle \mathrm{LVP}=1.0,1.6$ or 2.2 and with no fragmentation. The initial SOA gas-phase precursor concentration (termed $[\mathrm{HC}]_{0}$ ) was set for each $\triangle \mathrm{LVP}$ and $N_{\mathrm{C}}$ pair to yield $C_{\mathrm{OA}}=10 \mu \mathrm{g} \mathrm{m}^{-3}$ at 1 oxidation lifetime $\left(N_{\tau}=1\right)$, assuming that only 1 oxygen is added per reaction (i.e. $P_{\text {func }}=[1,0,0,0]$ ). This last assumption will be later relaxed to explore the influence of oxygen addition on the SOA formation. It is assumed that the SOA precursor is a saturated hydrocarbon; implications of having oxygenated SOA precursors are explored in Sect. 3.3.3.
There is a direct relationship between $N_{\mathrm{C}}$ and the calculated mean $\mathrm{O}: \mathrm{C}$, with smaller $N_{\mathrm{C}}$ values producing aerosol with larger $\mathrm{O}: \mathrm{C}$ (Fig. 2b). The variation in $\mathrm{O}: \mathrm{C}$ with $N_{\mathrm{C}}$ for a given $\triangle \mathrm{LVP}$ follows a power law relationship. The calculated $\mathrm{O}: \mathrm{C}$ has some dependence on $\triangle \mathrm{LVP}$ and is somewhat larger for smaller $\triangle \mathrm{LVP}$, and the overall sensitivity of model $\mathrm{O}: \mathrm{C}$ to $\triangle \mathrm{LVP}$ for a given $N_{\mathrm{C}}$ decreases with increasing carbon number of the SOA precursor. The $\triangle \mathrm{LVP}$ dependence is an expected result since a given SOA precursor must react more times (add more oxygen) in order to achieve sufficiently low volatility to partition to the aerosol when $\triangle \mathrm{LVP}$ is small.

There is also a relationship between the calculated aerosol yield and both $N_{\mathrm{C}}$ and $\triangle \mathrm{LVP}$. (Aerosol yield is defined as $C_{\mathrm{OA}} / \Delta[\mathrm{HC}]$, where $\Delta[\mathrm{HC}]$ is the amount of hydrocarbon reacted.) Larger $N_{\mathrm{C}}$ species tend to produce larger yields, although without fragmentation the SOM indicates that even small compounds $\left(N_{\mathrm{C}}<10\right)$ can produce SOA with relatively large yields. The relatively large yields of the smaller $N_{\mathrm{C}}$ compounds result from the more rapid increase in $k_{\mathrm{OH}}$ with oxygen addition for the small compounds in the SOMreactivity relationship. Larger $\triangle \mathrm{LVP}$ results in higher yields for a given $N_{\mathrm{C}}$ (Fig. 2c). Since $C_{\mathrm{OA}}$ for all simulations was the same, this variation in yield is driven entirely by the need for larger $[\mathrm{HC}]_{0}$ values at smaller $\triangle \mathrm{LVP}$ for a given precursor (cf. Table 1); as $\triangle$ LVP decreases a greater amount of initial (gas-phase) mass is needed to produce a fixed amount of aerosol after one lifetime of oxidation.

The explicit time evolution of the mean particle $\mathrm{O}: \mathrm{C}$ is considered to understand how this intensive property is expected to vary throughout a typical laboratory photooxidation experiment. Results are shown for $N_{\mathrm{C}}=12$ assuming $\Delta \mathrm{LVP}=1.6$ and 1 oxygen added per reaction and using $[\mathrm{HC}]_{0}=7.9 \mathrm{ppb}$ at $[\mathrm{OH}]=2.1 \times 10^{6}$ molecules $\mathrm{cm}^{-3}$ (which gives $C_{\mathrm{OA}}=10 \mu \mathrm{g} \mathrm{m}^{-3}$ over $10 \mathrm{~h}=1$ lifetime). Initially the $\mathrm{O}: \mathrm{C}$ is near zero and then increases rapidly, before plateauing and slowly decreasing with time (Fig. 3a). However, these rapid changes in the $\mathrm{O}: \mathrm{C}$ occur primarily when the $C_{\mathrm{OA}}<0.01 \mathrm{\mu g} \mathrm{m}^{-3}$. If the period where $C_{\mathrm{OA}}<0.01 \mu \mathrm{g} \mathrm{m}^{-3}$ is excluded, which is below the detection of most modern instrumentation, the $\mathrm{O}: \mathrm{C}$ is seen to continuously, albeit slowly decrease as aerosol forms (Fig. 3b). This behavior is due to a competition between the production rate of lower-volatility species with high $\mathrm{O}: \mathrm{C}$ and the increase in $C_{\mathrm{OA}}$, which, as it increases, enhances the partitioning of somewhat higher volatility species with lower $\mathrm{O}: \mathrm{C}$ to the particle phase. However, it is not only the increasing $C_{\mathrm{OA}}$, but also the increasing concentrations of the individual product molecules that drives up the particle-phase abundance. For the $N_{\mathrm{C}}=12$ species considered here, the overall variation in $\mathrm{O}: \mathrm{C}$ with $C_{\mathrm{OA}}$ over the range $0.1 \mu \mathrm{g} \mathrm{m}^{-3}<C_{\mathrm{OA}}<10 \mu \mathrm{g} \mathrm{m}^{-3}$ is relatively small, with $\mathrm{O}: \mathrm{C}$ decreasing from 0.36 to 0.30 . However, if the simulation is allowed to run for longer times, corresponding to $N_{\tau}>1$, there is an eventual turn-over in the $\mathrm{O}: \mathrm{C}$ such that it begins to increase with time (discussed 
Table 1. Initial hydrocarbon concentrations for the calculations shown in Fig. 2.

\begin{tabular}{|c|c|c|c|c|c|}
\hline$N_{\mathrm{C}}$ & $\begin{array}{c}{[\mathrm{OH}]} \\
\left(\text { molecules } \mathrm{cm}^{-3}\right)\end{array}$ & $\begin{array}{c}{[\mathrm{HC}]_{0}(\mathrm{ppb})} \\
\Delta \mathrm{LVP}=1.6 \\
\text { No fragmentation }\end{array}$ & $\begin{array}{c}{[\mathrm{HC}]_{0}(\mathrm{ppb})} \\
\Delta \mathrm{LVP}=1.0 \\
\text { No fragmentation }\end{array}$ & $\begin{array}{c}{[\mathrm{HC}]_{0}(\mathrm{ppb})} \\
\Delta \mathrm{LVP}=2.2 \\
\text { No fragmentation }\end{array}$ & $\begin{array}{c}{[\mathrm{HC}]_{0}(\mathrm{ppb})} \\
\Delta \mathrm{LVP}=1.6 \\
\text { Fragmentation }\end{array}$ \\
\hline 5 & $5.0 \times 10^{6}$ & 21.3 & 431.3 & 11.3 & 602.0 \\
\hline 6 & $3.7 \times 10^{6}$ & 19.9 & 182.2 & 8.7 & 343.2 \\
\hline 7 & $2.9 \times 10^{6}$ & 15.1 & 116.6 & 9.0 & 197.1 \\
\hline 8 & $2.4 \times 10^{6}$ & 14.6 & 76.5 & 9.1 & 130.9 \\
\hline 9 & $2.1 \times 10^{6}$ & 14.3 & 52.1 & 8.5 & 89.2 \\
\hline 10 & $1.8 \times 10^{6}$ & 13.6 & 44.4 & 7.7 & 60.7 \\
\hline 11 & $1.6 \times 10^{6}$ & 12.2 & 39.0 & 7.1 & 40.3 \\
\hline 12 & $1.5 \times 10^{6}$ & 10.2 & 32.3 & 6.1 & 26.1 \\
\hline 13 & $1.3 \times 10^{6}$ & 8.2 & 24.9 & 4.9 & 17.4 \\
\hline 14 & $1.2 \times 10^{6}$ & 6.6 & 18.0 & 4.0 & 11.5 \\
\hline 15 & $1.1 \times 10^{6}$ & 5.1 & 12.5 & 3.3 & 7.9 \\
\hline 16 & $1.0 \times 10^{6}$ & 3.9 & 8.4 & 2.9 & 5.3 \\
\hline 17 & $9.6 \times 10^{5}$ & 3.1 & 5.7 & 2.4 & 3.8 \\
\hline 18 & $9.0 \times 10^{5}$ & 2.4 & 3.9 & 1.9 & 2.8 \\
\hline 19 & $8.5 \times 10^{5}$ & 1.9 & 2.7 & 1.6 & 2.1 \\
\hline 20 & $8.0 \times 10^{5}$ & 1.5 & 1.9 & 1.4 & 1.6 \\
\hline
\end{tabular}

further in Sect. 3.3).The magnitude of the decrease when $N_{\tau}<1$ does depend somewhat on $N_{\mathrm{C}}$; larger decreases are generally found for smaller $N_{\mathrm{C}}$ compounds (not shown). There is also some dependence of the $\mathrm{O}: \mathrm{C}$ results on the assumed $[\mathrm{HC}]_{0}$. For example, if smaller $[\mathrm{HC}]_{0}$ values are specified to give smaller $C_{\mathrm{OA}}$ after $10 \mathrm{~h}$ of reaction, the $\mathrm{O}: \mathrm{C}$ is generally slightly larger than that calculated at an equivalent $C_{\mathrm{OA}}$ during the $C_{\mathrm{OA}}=10 \mu \mathrm{g} \mathrm{m}^{-3}$ (at $10 \mathrm{~h}$ ) simulations (Fig. 3b).

In broad terms, SOA precursors can be classified as volatile organic compounds (VOC, $C^{*}>10^{6} \mu \mathrm{g} \mathrm{m}^{-3}$ ), intermediate volatility organic compounds (IVOC, $10^{6}$ $\left.\mu \mathrm{g} \mathrm{m}^{-3}>C^{*}>10^{3} \mu \mathrm{g} \mathrm{m}^{-3}\right)$ or as semi-volatile organic compounds (SVOC, $C^{*}<10^{3} \mu \mathrm{g} \mathrm{m}^{-3}$ ) (Jathar et al., 2011). Using these designations, saturated hydrocarbons with $N_{\mathrm{C}}<12$ are VOCs, $12 \leq N_{\mathrm{C}}<18$ are IVOCs and $N_{\mathrm{C}} \geq 18$ are SVOCs (Fig. 2a). (SOA precursors that contain oxygen atoms will begin with a lower volatility for a given $N_{\mathrm{C}}$ and an $\mathrm{O}: \mathrm{C}>0$, thus altering these designations somewhat.) Figure $2 \mathrm{~b}$ indicates that only those compounds with $\sim 11$ or fewer carbon atoms produce $\mathrm{OA}$ with $\mathrm{O}: \mathrm{C}>0.4$ after 1 lifetime of oxidation, which corresponds to an atmospheric timescale of approximately 1-2 days at $\sim 2 \times 10^{6}$ molecules $\mathrm{cm}^{-3}$. To obtain an $\mathrm{O}: \mathrm{C}>0.8$, which has been observed for the most oxidized organic aerosol factor in ambient measurements $(\mathrm{Ng}$ et al., 2011), requires the SOA precursor to have less than 8 or so carbon atoms. This suggests that gas-phase processing coupled with equilibrium partitioning of saturated IVOC's and SVOC's (with $N_{\mathrm{C}} \geq 12$ ) will primarily lead to the formation of SOA with relatively low $\mathrm{O}: \mathrm{C}$ values $(<\sim 0.4)$ at these levels of oxidation (although the exact $N_{\mathrm{C}}$ ranges de- rived are somewhat sensitive to the specific model parameters used, cf. Fig. 2b). As will be discussed below, this conclusion is, to a reasonable extent, independent of consideration of fragmentation (Sect. 3.1.2) or whether the SOA precursor has oxygen-containing functional groups (Sect. 3.3.3). This conclusion does not account for the potential influence of condensed or aqueous phase reactions not included in the SOM that modify the SOA atomic composition.

\subsubsection{Fragmentation included}

In principle, $\mathrm{C}-\mathrm{C}$ bond scission reactions can have a controlling influence on aerosol yields and the kinetics of aerosol growth, with systems for which fragmentation is greater having smaller yields (Ziemann, 2011). In the model, it is possible to explicitly consider to what extent this occurs. The role of fragmentation is considered using the $N_{\mathrm{C}}=12$ SOA precursor as a test case. The probability of fragmentation is varied by adjusting the parameter $c_{\text {frag }}$ in Eq. (4) over the range 0.1 to 0.4 . (In Sect. 3.2 it will be shown that this range of $c_{\text {frag }}$ is consistent with laboratory experiments.) The general results are unchanged if the $P_{\text {frag }}$ expression in Eq. (5) is instead used. Two cases will be considered, one (case A) where the $[\mathrm{HC}]_{0}$ is fixed and one (case B) where $[\mathrm{HC}]_{0}$ is allowed to vary with $c_{\text {frag }}$ to maintain $C_{\mathrm{OA}}\left(N_{\tau}=1\right)=10 \mu \mathrm{g} \mathrm{m}^{-3}$. For case $\mathrm{A},[\mathrm{HC}]_{0}=10.3 \mathrm{ppb}$ is used, which gives $C_{\mathrm{OA}}\left(N_{\tau}=1\right)$ $=10 \mu \mathrm{g} \mathrm{m}^{-3}$ when $c_{\text {frag }}=0$. In all cases, $\Delta \mathrm{LVP}=1.6$ and $P_{\text {func }}=[1,0,0,0]$. (Note that other $P_{\text {func }}$ arrays have also been considered, where either a greater number of oxygens or distributions of oxygens are added per reaction, and consistent results to those discussed below are obtained.) 

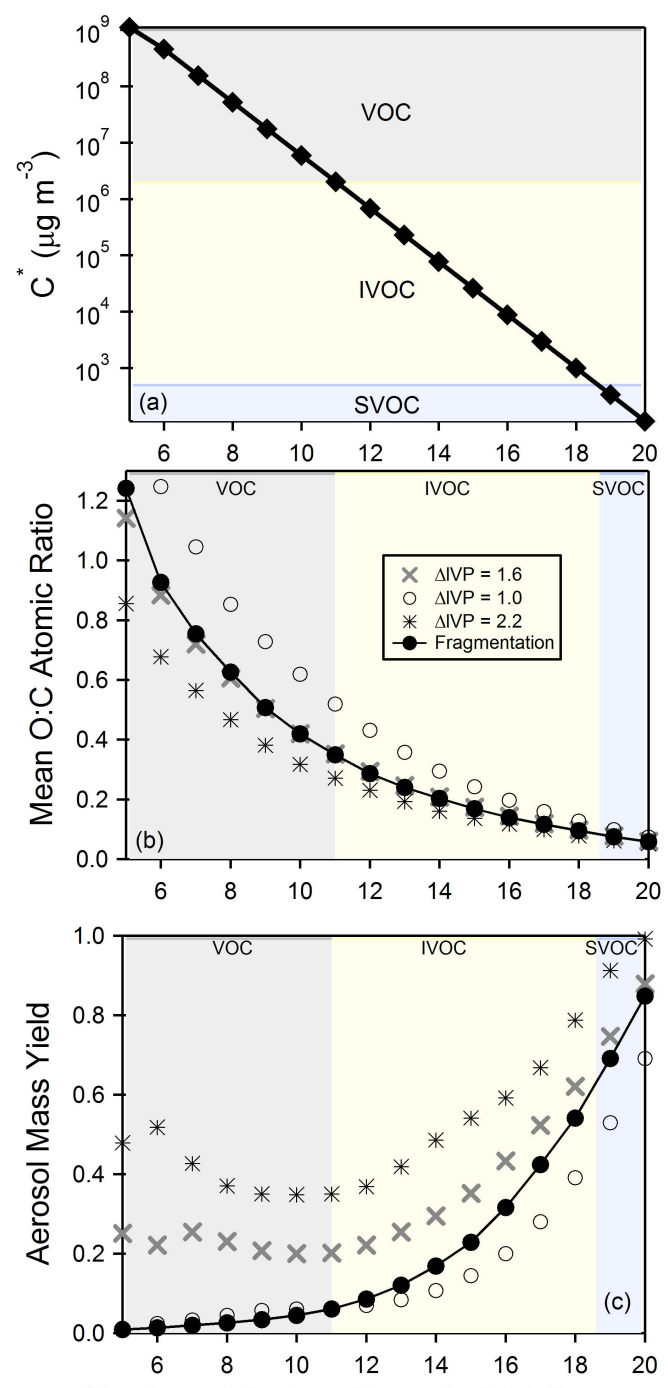

Number of Carbon Atoms in SOA Precursor

Fig. 2. (a) The relationship between volatility $\left(C^{*}\right.$, in $\left.\mu \mathrm{g} \mathrm{m}^{-3}\right)$ and number of carbon atoms (for a saturated hydrocarbon), showing the distinction between VOCs (gray), IVOCs (yellow) and SVOCs (blue). The calculated mean $\mathrm{O}: \mathrm{C}$ (b) and aerosol mass yield (c) are shown as a function of the number of carbon atoms in the SOA precursor. Results are shown for a variety of conditions with respect to changes in volatility upon oxygen addition and to fragmentation (see legend). All calculations are for $C_{\mathrm{OA}}=10 \mu \mathrm{g} \mathrm{m}^{-3}$ formed over 1 oxidation lifetime. Note that if the SOA precursors contained oxygen atoms, the VOC/IVOC/SVOC dividing lines would be shifted towards smaller $N_{\mathrm{C}}$.

For case A, the amount of aerosol produced at $N_{\tau}=1$ drops precipitously as $c_{\text {frag }}$ increases, with $C_{\mathrm{OA}}=5.6$ and $1.9 \mu \mathrm{g} \mathrm{m}^{-3}$, for $c_{\text {frag }}=0.1$ and 0.2 , respectively. This corresponds to a decrease in the aerosol yield from 0.22 to 0.12 or 0.04 for $c_{\text {frag }}=0.1$ or 0.2 , respectively. For $c_{\text {frag }}=0.3$ and 0.4 , the predicted $C_{\mathrm{OA}}$ is $<0.01 \mu \mathrm{g} \mathrm{m}^{-3}$. For case $\mathrm{B}$, the aerosol yield also decreases as $c_{\text {frag }}$ increases, to $0.15,0.09$,
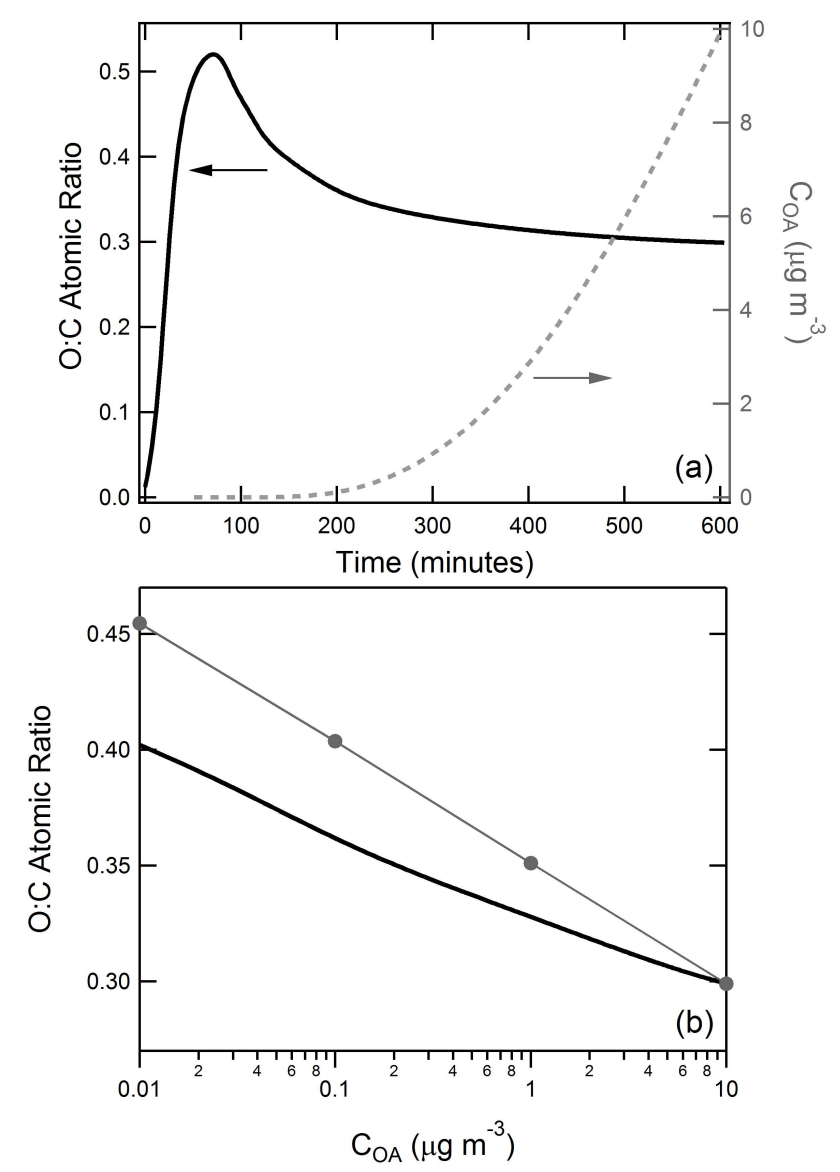

Fig. 3. (a) Temporal evolution of the mean aerosol $\mathrm{O}: \mathrm{C}$ atomic ratio (left axis, black line) and the organic aerosol mass $\left(C_{\mathrm{OA}}\right.$, right axis, gray dashed line) over 1 oxidation lifetime. (b) The time-variation in the calculated $\mathrm{O}: \mathrm{C}$ with $C_{\mathrm{OA}}$ shown over the instrumentally relevant range (i.e. $>0.01 \mu \mathrm{g} \mathrm{m}^{-3}$, corresponding to $t>200 \mathrm{~min}$ in (a), black line). Shown for comparison is the $\mathrm{O}: \mathrm{C}$ calculated after forming a specific amount of OA over 1 oxidation lifetime (gray circles). Calculations are for the no fragmentation case for $N_{\mathrm{C}}=12$ over 1 oxidation lifetime.

0.04 and 0.02 for $c_{\text {frag }}=0.1-0.4$, respectively. Thus, as expected, the inclusion of fragmentation in the model leads to decreases in the calculated aerosol yield, all other parameters being equal.

In addition to influencing aerosol yields, fragmentation should lead to OA with a higher $\mathrm{O}: \mathrm{C}$ than without fragmentation. This is because smaller molecules require more oxygen in order to partition to the particle phase, and thus the production of smaller molecules via fragmentation should drive up the $\mathrm{O}: \mathrm{C}$. However, the corresponding change in the calculated $\mathrm{O}: \mathrm{C}$ for the above cases is relatively small. For case $\mathrm{A}$, the $\mathrm{O}: \mathrm{C}$ increases from 0.29 with no fragmentation to 0.31 or 0.32 for $c_{\text {frag }}=0.1$ and 0.2 , respectively. For case $\mathrm{B}$, the calculated $\mathrm{O}: \mathrm{C}$ remains constant at 0.29 for $c_{\text {frag }}=0.1$ and 0.2 and then decreases slightly as $c_{\text {frag }}$ increases further, to 0.25 when $c_{\text {frag }}=0.4$. Overall it is found 
that fragmentation has a much larger influence on the calculated aerosol yield than it does on the $\mathrm{O}: \mathrm{C}$ and that fragmentation in the gas-phase is an inefficient way to increase the $\mathrm{O}: \mathrm{C}$ of SOA (at least in the absence of aqueous phase reactions that are not considered here, but that could lead to enhanced uptake of small carbonyl compounds).

Since intuition might suggest that the $\mathrm{O}: \mathrm{C}$ of $\mathrm{OA}$ should increase when fragmentation is included, it is important to consider in some detail why this is not always the case. First, although fragmentation does lead to the production of species that have a higher $\mathrm{O}: \mathrm{C}$ before partitioning to the particle phase (i.e. species with $N_{\mathrm{C}}<\mathrm{SOA}$ precursor), these species ultimately contribute very little to the total OA mass. For the specific cases considered above, $>80 \%$ of the OA mass is typically comprised of compounds with $N_{\mathrm{C}}$ equal to the SOA precursor compound (this percent varies with the parent $N_{\mathrm{C}}$ ). Much of the material with $N_{\mathrm{C}}$ equal to the SOA precursor condenses efficiently to the particle phase before fragmentation, which by itself limits the gas-phase production rate of smaller $N_{\mathrm{C}}$ compounds. Additionally, the fragments themselves have a greater probability of fragmenting prior to condensation because they persist longer in the gas-phase and must undergo additional reactions to obtain a sufficiently high oxygen content to facilitate efficient condensation. In other words, the more times that a molecule reacts, the more chances it has to fragment (i.e. the total fragmentation probability for a given molecule is the product of the $P_{\text {frag }}$ terms for prior reactions). Finally, because we assume that the probability of fragmentation scales with oxygen content, fragmentation will serve to depress somewhat the formation of the highest $\mathrm{O}: \mathrm{C}$ species. In Fig. 4 the probability distribution of having $n$-oxygens per molecule in the particle-phase is shown for the no-fragmentation case and for $c_{\text {frag }}=0.2$ for case B. Overall, fragmentation moves the oxygen distribution towards molecules with fewer oxygen atoms, at least on the $N_{\tau}=1$ timescale considered here (the behavior at larger $N_{\tau}$ is considered in Sect. 3.3.1).

If the same calculations are performed for other $N_{\mathrm{C}}$ compounds (from 5-20 carbon atoms), it is found that, in general, fragmentation leads to small changes in $\mathrm{O}: \mathrm{C}$ compared to the equivalent non-fragmentation case. Calculations of $\mathrm{O}: \mathrm{C}$ and the aerosol yield as a function of $N_{\mathrm{C}}$ are shown in Fig. $2 \mathrm{~b}$ for $\Delta \mathrm{LVP}=1.6, c_{\text {frag }}=0.2, P_{\text {func }}=[1,0,0$, $0]$ and $C_{\mathrm{OA}}\left(N_{\tau}=1\right)=10 \mu \mathrm{g} \mathrm{m}^{-3}$. Although fragmentation does not typically lead to a substantial change in the mean particle $\mathrm{O}: \mathrm{C}$, compared to the equivalent non-fragmentation case, it does strongly influence the calculated aerosol yield, with the influence of fragmentation becoming greater as $N_{\mathrm{C}}$ decreases (Fig. 5). As already discussed, fragmentation suppresses OA formation and thus a greater amount of initial hydrocarbon is necessary to produce the same $C_{\mathrm{OA}}$ at a given $\mathrm{OH}$ exposure. This serves to decrease the aerosol yield. The effect is much more pronounced for small compounds because these compounds must undergo many more gas-phase reactions compared to larger ones before sufficient oxygen is

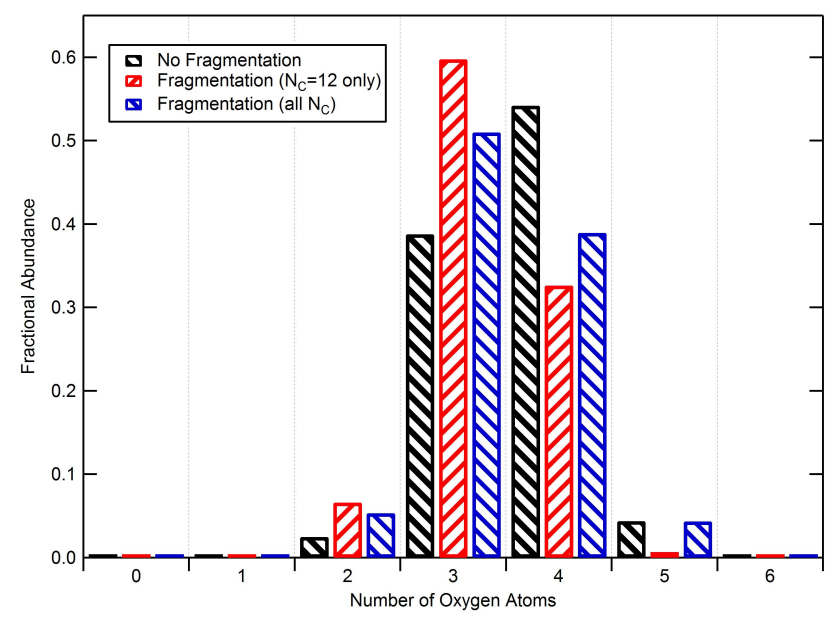

Fig. 4. Calculated distribution of oxygen atoms in the particle-phase after 1 lifetime of reaction for a $N_{\mathrm{C}}=12 \mathrm{SOA}$ precursor for cases without fragmentation and with fragmentation (see legend).

added to facilitate efficient condensation. Fragmentation will have a more pronounced influence on yields if smaller values of $\triangle$ LVP are assumed because, again, molecules must go through more reactions to add sufficient oxygen. Thus, the overall influence of fragmentation is largest for small compounds and when $\triangle$ LVP is small. Additionally, if the fragmentation probability (i.e. $c_{\text {frag }}$ ) is assumed to be larger, the ratio between yields with and without fragmentation grows. If the $P_{\text {frag }}$ becomes large enough, OA formation can be completely suppressed in the SOM. Future work will be focused on constraining the fragmentation operator (both the magnitude and the functional form) based on comparisons with laboratory smog chamber aerosol growth experiments.

To relate the output of the SOM to other model formulations, such as the VBS, the distributions of individual compounds can be binned by mass into logarithmically spaced $C^{*}$ bins, and the evolution of this distribution throughout a reaction can be calculated. An example is shown in Fig. 6 for the $N_{\mathrm{C}}=12$ case B simulation with $c_{\text {frag }}=0.2$ from above, although now the simulation has been run for many more lifetimes of oxidation (up to $N_{\tau}=5$ is shown). The distribution of products comprising both the total and the particlephase only are continuously evolving, as expected given the continued reactivity of the products, and gas-phase products with volatility greater than the parent hydrocarbon are produced as a result of fragmentation. The evolution of the total (gas + particle) provides a visual example of the statistical nature of the oxidation process in the SOM (similar to that in Fig. 1), while the particle-phase shows the combined effects of volatility, reactivity, the abundance of compounds in a given $\log C^{*}$ bin and the total $C_{\mathrm{OA}}$. That the product yields are not static as a reaction proceeds, particularly at short lifetimes $\left(N_{\tau}<1\right)$, has implications for the interpretation of laboratory aerosol yield curves from photooxidation 


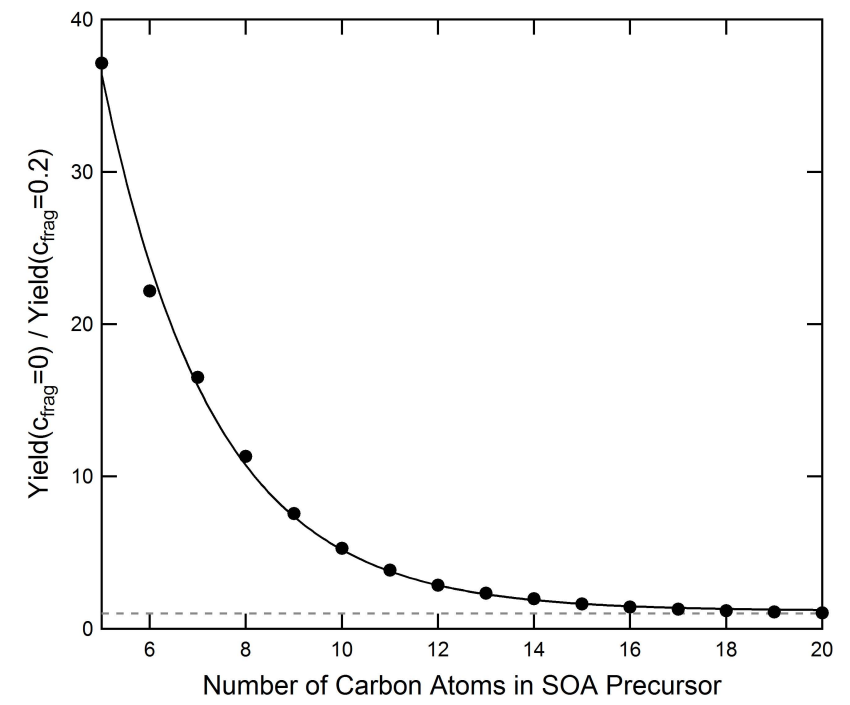

Fig. 5. The ratio between the aerosol yield calculated without and with fragmentation (assuming $c_{\text {frag }}=0.2, \Delta \mathrm{LVP}=1.6$ and $\left.C_{\mathrm{OA}}\left(N_{\tau}=1\right)=10 \mu \mathrm{g} \mathrm{m}^{-3}\right)$. The line is a power law fit.

experiments when such interpretations are formulated in terms of static yields, as with the 2-product model (Odum et al., 1996) or static VBS (Donahue et al., 2006).

\subsubsection{Oxygen addition}

In the previous sections, it was assumed that each reaction with $\mathrm{OH}$ led to the addition of only 1 oxygen atom. In this case, for a molecule to obtain e.g. 5 oxygen atoms it would undergo at least 5 reactions. It is possible for some reactions to add more than 1 oxygen, most notably for the oxidation of aromatic compounds or of compounds containing double bonds, but also potentially for saturated compounds. In the SOM, up to 4 oxygen atoms can be added per reaction, where we assume, given the molecular complexity of oxidation mechanisms, that some distribution of oxygen atoms are added per reaction (e.g. $50 \%$ add 1 oxygen and $50 \%$ add 2 oxygens). Below, the general influence of the assumed number of oxygens per reaction on the $\mathrm{O}: \mathrm{C}$ and aerosol yield is explored.

Consider a SOA precursor compound that adds 1, 2, 3 or 4 oxygens per reaction. The more oxygens that are assumed to be added per reaction, the faster that the system will form "low" volatility compounds that can condense efficiently to the particle phase (assuming a constant $\triangle \mathrm{LVP}$ ). Further, if fragmentation is included, because compounds that add more oxygen atoms per reaction ultimately go through fewer reactions prior to condensation, the influence of fragmentation can be suppressed. This is true even though $P_{\text {frag }}$ for an individual species is assumed to depend on the oxygen content, since it is the net fragmentation probability that most matters to the system (which is determined by the combi-

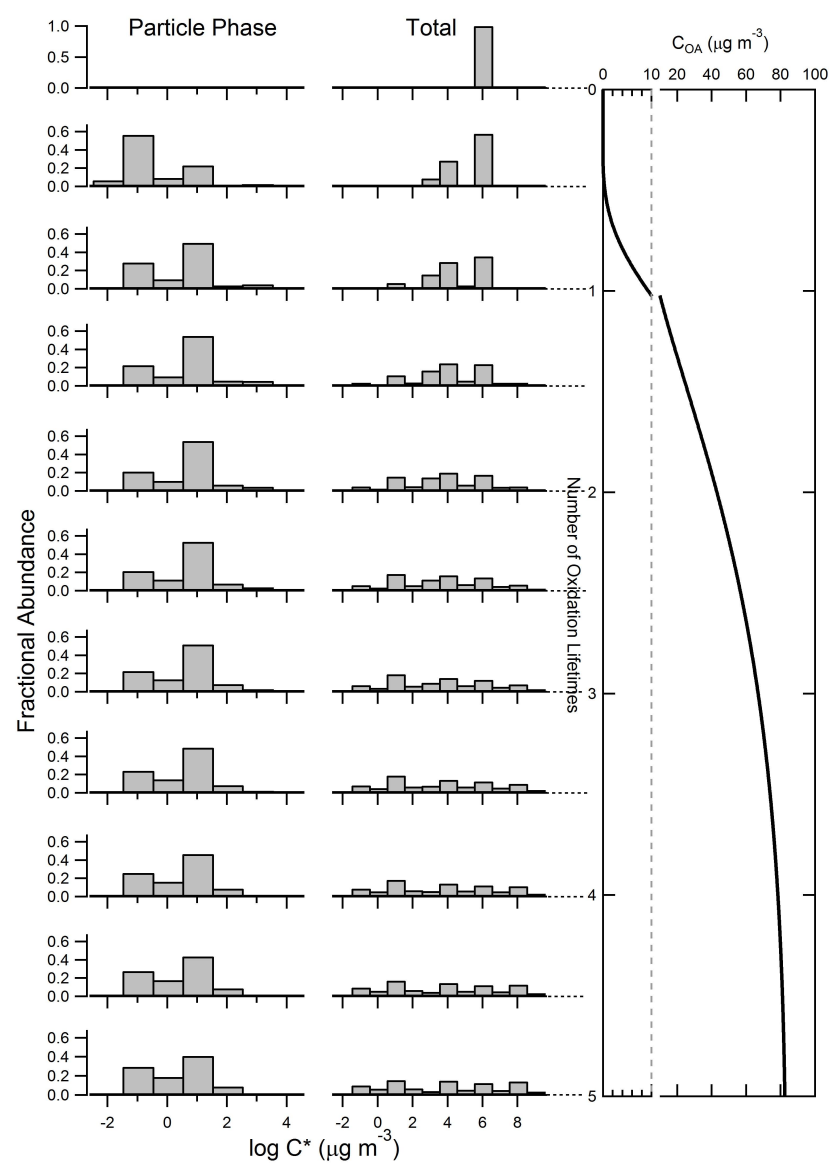

Fig. 6. Histograms showing the variation in the particle phase and total mass distributions when binned into logarithmically-spaced volatility bins, as a function of the number of oxidation lifetimes. Calculations are for a $N_{\mathrm{C}}=12 \mathrm{SOA}$ precursor, including fragmentation. For reference, the variation in the $C_{\mathrm{OA}}$ with lifetimes is shown.

nation of the number of reactions and the specific $P_{\text {frag }}$ values). As a specific example, again a $N_{\mathrm{C}}=12$ SOA precursor is used. The time-evolution in $C_{\mathrm{OA}}$, aerosol yield and $\mathrm{O}: \mathrm{C}$ have been calculated for addition of $1,2,3$ or 4 oxygens per reaction (Fig. 7). The $[\mathrm{HC}]_{0}$ were selected to produce $C_{\mathrm{OA}}=10 \mu \mathrm{g} \mathrm{m}^{-3}$ after 3 oxidation lifetimes, assuming $\Delta \mathrm{LVP}=1.6$ and no fragmentation. For comparison, calculations were performed assuming that $P_{\text {func }}=[0.25,0.25$, $0.25,0.25]$ with $\triangle \mathrm{LVP}=1.0,1.6$ or 2.2 .

The assumed number of oxygens per reaction has a strong influence on the temporal evolution of the aerosol mass and the shape of yield and growth curves (Fig. 7). For example, there is a long time-lag before significant OA forms for the 1-oxygen case, whereas for the 4-oxygen case OA is formed nearly instantaneously. This difference should not be surprising, since the addition of more oxygen atoms per reaction leads to more rapid production of sufficiently low volatility material, and thus OA will form at a faster rate. However, 

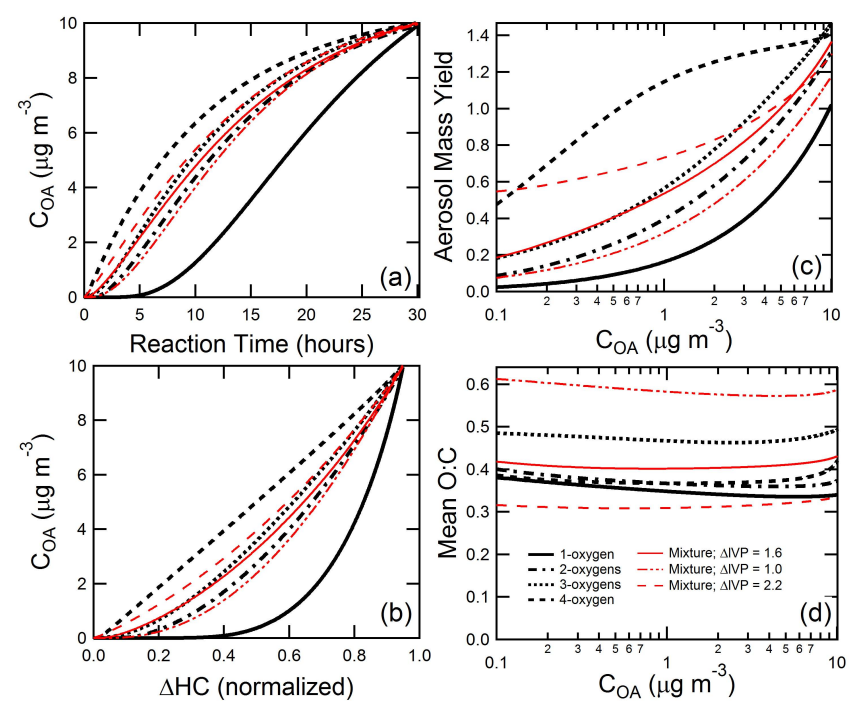

Fig. 7. The (a) temporal evolution of the aerosol mass, (b) variation of $C_{\mathrm{OA}}$ with the amount of SOA precursor reacted, (c) variation of aerosol yield with $C_{\mathrm{OA}}$, and (d) variation of $\mathrm{O}: \mathrm{C}$ with $C_{\mathrm{OA}}$ shown for the addition of $1,2,3$ or 4 oxygen atoms per reaction for a $N_{\mathrm{C}}=12$ SOA precursor over 3 lifetimes of oxidation, assuming $\Delta \mathrm{LVP}=1.6$. Results are also shown assuming $P_{\text {func }}=[0.25,0.25$, $0.25,0.25]$ with $\Delta \mathrm{LVP}=1.0,1.6$ or 2.2 .

it does suggest an important result, namely that the shape of a growth curve and the temporal evolution of OA formation can together be used to deduce the approximate number of oxygens added per reaction for a given system. Consider the low- $\mathrm{NO}_{\mathrm{x}}$ oxidation of toluene, as an example $(\mathrm{Ng}$ et al., 2007b). For this system, the growth curve (i.e. $C_{\mathrm{OA}}$ vs. $\Delta[\mathrm{HC}]$ ) is nearly linear, suggesting that 3 or 4 oxygens are added per reaction, which is consistent with the low- $\mathrm{NO}_{\mathrm{x}}$ oxidation mechanism ( $\mathrm{Ng}$ et al., 2007b). It should be noted, however, that in the SOM it is currently assumed that the gasparticle system reaches equilibrium instantaneously. If there are kinetic limitations to SOA formation then the yield curves will be altered accordingly.

Traditionally, growth curves are presented as $C_{\mathrm{OA}}$ vs. $\Delta[\mathrm{HC}]$, the amount of SOA precursor reacted. To facilitate comparison with results from the SOM as well as between different experiments, we suggest it is useful to present growth curves with the $\mathrm{x}$-axis as a fraction of the total initial hydrocarbon reacted $\left(f_{\mathrm{HC}}\right)$, in addition to $C_{\mathrm{OA}}$ vs. the absolute change in the hydrocarbon concentration. By using $f_{\mathrm{HC}}$, one can more easily identify the point at which all (or nearly all) of the hydrocarbon has reacted.

For a fixed $\triangle \mathrm{LVP}$, there is a relatively weak dependence of $\mathrm{O}: \mathrm{C}$ on the assumed oxygens per reaction, although the specific dependence shown in Fig. $7 \mathrm{~d}$ is non-intuitive. Consider that, for the $N_{\mathrm{C}}=12$ case here, the 3-oxygens per reaction case gives the highest $\mathrm{O}: \mathrm{C}$. This specific result can be understood as follows: under the specified conditions, the $N_{\mathrm{C}}=12, N_{\mathrm{O}}=3$ compound has a volatility of $C^{*}=$
$10.7 \mu \mathrm{g} \mathrm{m}^{-3}$. At $C_{\mathrm{OA}}=10 \mu \mathrm{g} \mathrm{m}^{-3}$, a significant amount of material remains in the gas-phase available to undergo further reactions that add 3 additional oxygens. In contrast, for the 4-oxygens per reaction case, the very low volatility of the first-generation products makes subsequent gas-phase reactions and oxygen addition very slow. As with the 4-oxygens per reaction case, for 1 or 2 oxygens per reaction the oxygen addition is slow once the precursor gas has added 4 oxygens. However, the molecular complexity of oxidation reactions suggests that a distribution of oxygens per reaction will likely be added, and thus, although illustrative, the cases considered above may not be general. To address this, calculations have been performed where it is assumed that 1,2, 3 and 4 oxygens are added per reaction with equal probability. In this case, the $\mathrm{O}: \mathrm{C}$ and $C_{\mathrm{OA}}$ evolve approximately as an average of the individual cases (Fig. 7d).

The number of oxygen atoms added per reaction is not the only factor that controls the shape of yield or growth curves. The specific value of $\triangle \mathrm{LVP}$ also influences the temporal evolution of the system by altering the rate at which sufficiently low volatility material is produced. The influence of $\Delta \mathrm{LVP}$ can be assessed by recalling that the likely range over which $\Delta \mathrm{LVP}$ varies is from 1 to 2.2 (a $\Delta$ of 1.2 ), which can then be compared to the influence of adding an additional oxygen. For a fixed $\triangle \mathrm{LVP}$, every additional oxygen will decrease the volatility by $\triangle \mathrm{LVP}$, which will usually be greater than the difference between the ketone-only $(\triangle \mathrm{LVP}=1)$ and alcoholonly $(\Delta \mathrm{LVP}=2.2)$ cases. Therefore, variations in the assumed number of oxygens added per reaction are expected to have a greater influence on the shape of the yield or growth curves than differences in the assumed $\triangle \mathrm{LVP}$, as is evident from Fig. 7b. However, $\triangle$ LVP has a particularly strong influence on the predicted $\mathrm{O}: \mathrm{C}$ for the multiple-oxygen-per reaction case (Fig. 7d), as was indicated earlier for the 1-oxygenper-reaction case shown in Fig. 2b. This suggests that experimental observations of the time evolution of both $C_{\mathrm{OA}}$ and $\mathrm{O}: \mathrm{C}$ can serve to provide constraints on the SOM parameters for a given reaction.

\subsubsection{Oxidation of multi-component mixtures}

Only single component SOA precursor reactions have been considered thus far. In the atmosphere, simultaneous oxidation of many different precursors occurs. To assess the potential generalizability of the single component results, oxidation simulations have been carried out for a mixture of precursor compounds, using $N_{\mathrm{C}}=15$ to $N_{\mathrm{C}}=5$. The initial gas-phase concentrations were adjusted such that after $10 \mathrm{~h}$ of simulation at $[\mathrm{OH}]=2 \times 10^{6}$ the total abundance of products from each of the individual precursors were approximately equal (around $0.9 \mu \mathrm{g} \mathrm{m}^{-3}$ each to give $C_{\mathrm{OA} \text {,total }}=10 \mu \mathrm{g} \mathrm{m}^{-3}$ ). So that products from individual precursors could be identified $c_{\text {frag }}$ was set to zero and for simplicity 1 oxygen was assumed added per reaction. The mean $\mathrm{O}: \mathrm{C}$ for each group of compounds originating from 
a specific precursor (i.e. $N_{\mathrm{C}}=15$ only) was calculated and can be compared with the $\mathrm{O}: \mathrm{C}$ values obtained from the single-compound simulations. For these specific conditions, the $\mathrm{O}: \mathrm{C}$ for compounds with $N_{\mathrm{C}}>13$ were negligibly increased (e.g. 0.17 to 0.176 for $N_{\mathrm{C}}=15$ ) while the $\mathrm{O}: \mathrm{C}$ for smaller compounds decreased slightly (e.g. 1.14 to 1.04 for $N_{\mathrm{C}}=5$ ). The differences were slight in all cases, indicating that the single-component results are general.

\subsection{Fitting of laboratory data}

\subsubsection{Time evolution of aerosol growth}

The SOM can be used to compute the time evolution of aerosol mass (or yields) and the mean O:C. The SOM can be fit to laboratory aerosol growth experiments by minimizing the chi-square difference between model and measurement; from this, best-fit SOM parameters can be determined. Here, we demonstrate the general process and utility of fitting the SOM to laboratory $C_{\mathrm{OA}}$ data using two examples: (1) $\alpha$ pinene photooxidation under low- $\mathrm{NO}_{\mathrm{x}}$ conditions ( $\mathrm{Ng}$ et al., 2007a) and (2) pentadecane photooxidation under high- $\mathrm{NO}_{\mathrm{x}}$ conditions (Presto et al., 2010). Future work will focus on fitting a variety of laboratory SOA formation data using the SOM in order to determine best-fit parameters for different experiments and establish how the parameters vary with reaction conditions (e.g. precursor identity, high vs. low $\mathrm{NO}_{\mathrm{x}}$ ).

Because $\alpha$-pinene contains a single double bond, the reaction rate of $\alpha$-pinene with $\mathrm{OH}$ is likely to be faster than that of its oxidation products. To account for this, the $k_{\mathrm{OH}}$ matrix has been modified to explicitly assign a value for the reaction of $\mathrm{OH}$ with $\alpha$-pinene $\left(k_{\mathrm{OH}}=5.3 \times 10^{-11}\right.$ molecules $\mathrm{cm}^{-3}$, Gill and Hites, 2002), with the rate coefficients of all other products computed using the SOM-reactivity relationship. $\mathrm{Ng}$ et al. (2007a) measured time-dependent aerosol formation for $\alpha$-pinene photooxidation under low- $\mathrm{NO}_{\mathrm{x}}$ conditions that can be computed by the SOM. The experimentallyconstrained model inputs are $[\mathrm{HC}]_{0}=13.8 \mathrm{ppb}$ and $[\mathrm{OH}]$ $\sim 3 \times 10^{6}$ molecules $\mathrm{cm}^{-3}$ (the exact $[\mathrm{OH}]_{t}$ was deduced by matching to the observed decay of $\alpha$-pinene), and the experiment ran for $N_{\tau} \sim 6$. The best-fit to the observations is obtained for: $\Delta \mathrm{LVP}=1.83, c_{\text {frag }}=0.18$, and $P_{\text {func }}=[0.0$, $0.46,0.42,0.12]$, (Fig. 8). (Note that because the distribution of products resulting from fragmentation are randomly generated each time the model is run one obtains a slightly different solution. However, the run-to-run variability is relatively small.) Use of Eq. (5) for $P_{\text {frag }}$ allows for a similarly good fit to the $C_{\mathrm{OA}}$ observations, with $\triangle \mathrm{LVP}=1.74, m_{\mathrm{frag}}=0.50$, and $P_{\text {func }}=[0.0,0.28,0.56,0.16]$. Of note is the similarity between the $\triangle \mathrm{LVP}$ and $P_{\text {func }}$ arrays for the two fragmentation parameterizations. The distribution of particulatephase compounds in $N_{\mathrm{C}} / N_{\mathrm{O}}$ space with fractional populations $>0.01 \%$ is also shown for select points along the simulated reaction (Fig. 8). The distribution of oxidation products evolves throughout the simulation, with compounds of lower



Fig. 8. (main graph) Time-dependent aerosol formation for $\alpha$ pinene photooxidation under low- $\mathrm{NO}_{\mathrm{x}}$ conditions comparing the calculated curve (line) to observations (points) ( $\mathrm{Ng}$ et al., 2007a). The calculated curve is colored by the mean $\mathrm{O}: \mathrm{C}$ of the OA. (inset) The aerosol growth curve (yield vs. $\Delta[\mathrm{HC}]$ ) for this system. (above) The small graphs show the distribution of products, colored by mole fraction in the condensed phase, at various points throughout the reaction (indicated by arrows) in oxygen/carbon space. The points in the upper-right graph indicate structures for compounds that have been observed to exist in the condensed phase with measurable yields.

$N_{\mathrm{C}}$, higher $N_{\mathrm{O}}$ contributing more significantly at later times, although at all times contributions of $N_{\mathrm{C}}=\mathrm{SOA}$ precursor species dominate.

The validity of these model results can be evaluated in light of what is known about the $\alpha$-pinene photooxidation mechanism. For $\alpha$-pinene oxidation, the $\mathrm{OH}$ addition pathway dominates $(90 \%)$, and condensed-phase products with 2, 3 and 4 oxygens have been observed (Larsen et al., 2001; Jaoui and Kamens, 2003). Some of these products have fewer carbon atoms than $\alpha$-pinene, indicating that fragmentation does occur. The model distribution of products in carbon/oxygen space can be compared with experimentally detected compounds. Figure 8 shows that there is generally good, although not perfect, agreement between the predicted and observed distribution of highly abundant compounds in terms of the $N_{\mathrm{C}}$ and $N_{\mathrm{O}}$ (Larsen et al., 2001; Jaoui and Kamens, 2003). The model O: $\mathrm{C}$ for the OA ranges from $\sim 0.38$ to 0.45 , which compares extremely well with observations $(\mathrm{O}: \mathrm{C}=0.40$, Chhabra et al., 2011). This comparison 


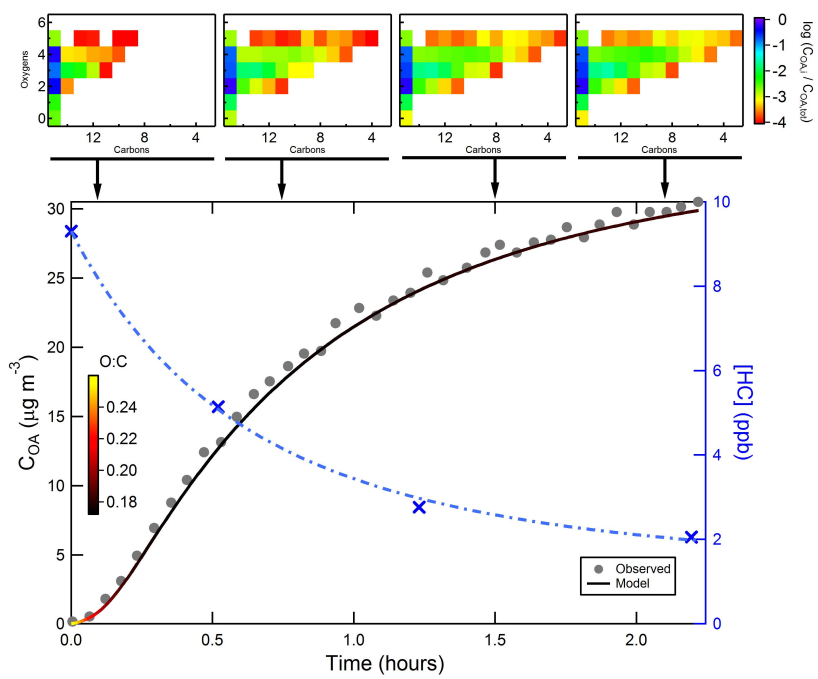

Fig. 9. The temporal evolution of $C_{\mathrm{OA}}$ (left axis) and [HC] (right axis) for photoxidation of pentadecane under high- $\mathrm{NO}_{\mathrm{x}}$ conditions for the model (lines) and measurements (symbols: $C_{\mathrm{OA}}=\bullet$ and $[\mathrm{HC}]=*)$. Measured values are from Presto et al. (2010). The calculated curve is colored by the mean $\mathrm{O}: \mathrm{C}$ of the OA. The small graphs show the distribution of products in the particle phase, colored by mole fraction, at various points throughout the reaction (indicated by arrows).

between model and experiment suggests that the SOM representation of oxidation in this system is a reasonable approximation of the chemistry, even though the $\Delta \mathrm{LVP}$ and $P_{\text {func }}$ arrays are assumed to be constant.

The model was also fit to the temporal evolution of the $C_{\mathrm{OA}}$ for the pentadecane $+\mathrm{OH}$ system from Presto et al. (2010) (cf. their Fig. 1). For this experiment, OH was not constant, and thus $\mathrm{OH}$ in the model is allowed to change so that the temporal behavior of the measured pentadecane concentrations can be replicated, with $[\mathrm{HC}]_{0}=9.3 \mathrm{ppb}$ and the overall $N_{\tau}=0.64$. Excellent model $/$ measurement agreement is obtained (Fig. 9), with the two fragmentation parameterizations giving (Eq. 4) $c_{\text {frag }}=0.23, \Delta \mathrm{LVP}=1.63$, and $P_{\text {func }}=[0.26,0.67,0.00,0.07]$ or (Eq. 5) $m_{\text {frag }}=0.38$, $\Delta \mathrm{LVP}=1.59$, and $P_{\text {func }}=[0.10,0.86,0.0,0.04]$ as best fits. The evolution of the particle-phase $N_{\mathrm{C}} / N_{\mathrm{O}}$ molecule distributions are also shown at selected points during the reaction, and indicate that the particle composition is continuously evolving, as expected.

The model predicts an $\mathrm{O}: \mathrm{C}$ of $\sim 0.19$. Presto et al. (2010) do not directly report $\mathrm{O}: \mathrm{C}$, but they do report the fraction of the aerosol mass spectrum at $m / z 44\left(f_{44}\right)$, which has been previously shown to have a relationship to $\mathrm{O}: \mathrm{C}$ (Aiken et al., 2008; Sun et al., 2009). Using the $f_{44}$ vs. O:C relationship, the $\mathrm{O}: \mathrm{C}$ for the high- $\mathrm{NO}_{\mathrm{x}}$ pentadecane $\mathrm{OA}$ is estimated to be $\sim 0.20$, although it should be noted that the $f_{44}$ for pentadecane OA is lower than the measurement range in both these papers and, from the data shown in Aiken et al. (2008), there

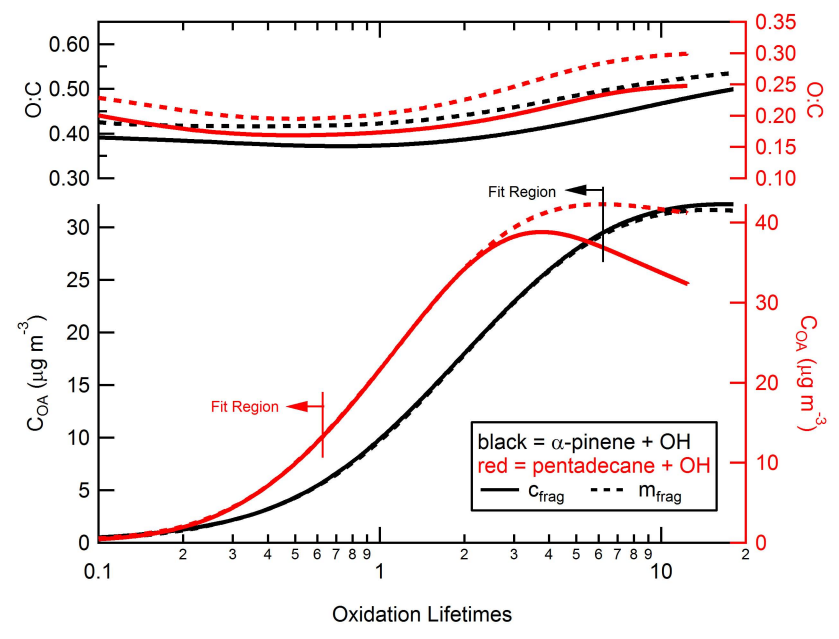

Fig. 10. Extrapolation to longer oxidation lifetimes of best-fit results for the two $P_{\text {frag }}$ parameterizations for $\alpha$-pinene $+\mathrm{OH}$ (black) and pentadecane $+\mathrm{OH}$ (red), shown for $C_{\mathrm{OA}}$ and $\mathrm{O}: \mathrm{C}$. The solid lines are for $P_{\text {frag }}=c_{\text {frag }} N_{\mathrm{O}}$ and the dashed lines for $P_{\text {frag }}=$ $(\mathrm{O}: \mathrm{C})^{m \text { frag }}$. The vertical lines indicate the point to which the model curves were constrained by observations.

is reason to suspect that this relationship may over-estimate $\mathrm{O}: \mathrm{C}$ at lower $f_{44}$ (cf. the "AMB ground" and "HOA ground" points in their Fig. 4). Given this uncertainty, the level of agreement between model and experiment is satisfactory.

Both these and the $\alpha$-pinene results above indicate that the selected functional form for $P_{\text {frag }}$ does not influence whether the SOM can be fit to the observations, so long as the tunable parameters $\left(c_{\text {frag }}\right.$ or $\left.m_{\text {frag }}\right)$ are set appropriately. However, when the SOM is extrapolated far beyond the fit range (with respect to the number of oxidation lifetimes), some differences in the continued evolution of the SOA mass and, to a lesser extent, the $\mathrm{O}: \mathrm{C}$ are found between the two fragmentation parameterizations (Fig. 10). This suggests that fitting of the SOM to experiments that are run over many oxidation lifetimes can provide stronger constraints on the best-fit parameters for a given reaction. Nonetheless, it is clear that the multi-generational model developed here provides a robust framework for modeling the formation and evolution of SOA.

The SOM has six adjustable parameters - the $\Delta \mathrm{LVP}, P_{\text {frag }}$ and $P_{\text {func }}$ array (recall that the $P_{\text {func }}$ is an array with 4 elements). Given the number of adjustable parameters, it is perhaps not surprising that the SOM can be fit with good fidelity to the above observations of SOA formation in chamber experiments. This also raises some questions regarding the uniqueness of the solution(s) obtained, and thus the interpretability of the derived parameters in terms of physical properties. One way in which stronger constraints can be placed on the best-fit parameters in the future is the simultaneous fitting to time-series of $\mathrm{O}: \mathrm{C}$ and $C_{\mathrm{OA}}$, instead of to $C_{\mathrm{OA}}$ only. This is because the model $\mathrm{O}: \mathrm{C}$ is particularly 
sensitive to the $\triangle$ LVP parameter. Additionally, for chemical systems (e.g. $\alpha$-pinene $+\mathrm{OH}$ ) for which data from multiple experiments run under the same conditions are available, the SOM can be fit to each of the experiments independently (or simultaneously) and the best-fit results compared. Finally, the generalizability of the SOM approach can be tested by fitting the model simultaneously to multiple experiments that were run under the same conditions but using different compounds within a given class, as is done in the next section.

\subsection{2 $\quad N_{\mathrm{C}}$ dependence of aerosol yield}

Lim and Ziemann (2005) measured aerosol yields for photooxidation of a series of straight-chain alkanes at high- $\mathrm{NO}_{\mathrm{x}}$ $\left(\left[\mathrm{NO}_{\mathrm{x}}\right] /[\mathrm{HC}] \sim 20 \mathrm{ppbppb}^{-1}\right)$ and at high $C_{\mathrm{OA}}(\sim 200-$ $5000 \mu \mathrm{g} \mathrm{m}^{-3}$ ), from $N_{\mathrm{C}}=8$ to 17 . (The aerosol yields reported in Lim and Ziemann (2005) were corrected in Jordan et al. (2008), and we use the corrected values here.) The aerosol yields for the conditions of these experiments have been simulated, where the $[\mathrm{HC}]_{0}$ are from Jordan et al. (2008) and the $[\mathrm{OH}]$ are specified to provide for the observed decay in each $[\mathrm{HC}]$ over $1 \mathrm{~h}$ of reaction (with $[\mathrm{OH}]$ typically $\sim 2 \times 10^{7}$ molecules $\mathrm{cm}^{-3}$ ). Note that timedependent growth curves are not available, and thus we fit only to the final yield reported for each experiment. In fitting the SOM to the observations, we have fit the yields for each of the alkanes simultaneously, i.e. a single set of values for the $\triangle \mathrm{LVP}, P_{\text {frag }}$ and $P_{\text {func }}$ parameters have been determined that correspond to the best-fit to all of the observed yields. We have fit the SOM to the reported yields only for the subset where $N_{\mathrm{C}} \leq 15$. The reason for excluding the yields for the $N_{\mathrm{C}}=16$ and 17 alkanes is that the volatilities of these molecules are sufficiently low and the concentrations sufficiently high at the start of the experiment that a significant amount of the $[\mathrm{HC}]_{0}$ ends up in the particle phase without undergoing any reaction; this complicates the definition of "yield" somewhat, as the yield now includes condensation of un-reacted parent compound.

The best-fit yield vs. $N_{\mathrm{C}}$ dependence agrees well with the observations (Fig. 11), with best-fit SOM parameters of (Eq. 4) $c_{\text {frag }}=0.45, \Delta \mathrm{LVP}=1.94$ and $P_{\text {func }}=[0.38,0.34$, $0.28,0.0]$ or (Eq. 5) $m_{\text {frag }}=0.16, \Delta \mathrm{LVP}=1.83$ and $P_{\text {func }}=$ $[0.38,0.62,0.0,0.0]$. These best-fit parameters can be compared with the best-fit parameters determined from fitting the time-dependent pentadecane SOA growth from Sect. 3.2.1; the $\triangle \mathrm{LVP}$ values here are larger and the fragmentation more extensive, compared to the time-dependent pentadecane fit. The differences between the best-fit parameters here and from the pentadecane fit from above likely results from the much higher $\left[\mathrm{NO}_{\mathrm{x}}\right] /[\mathrm{HC}]\left(\sim 150 \mathrm{ppb} \mathrm{ppb}^{-1}\right)$ and much lower $C_{\mathrm{OA}}$ in the Presto et al. (2010) experiments. Nonetheless, that a single set of parameters can capture the yield vs. $N_{\mathrm{C}}$ dependence is notable. Our results suggest that the SOM may be able to provide a general modeling framework for a given type of precursor (here, straight-chain alkanes) and reaction



Fig. 11. Calculated $N_{\mathrm{C}}$-dependent yields for straight-chain alkanes of varying $N_{\mathrm{C}}$ compared with observed yields from Jordan et al. (2008).

conditions, although this will need to be carefully assessed through further comparison with observations. It should be noted that Presto et al. (2010) similarly found that a single set of yield parameters could be used within the static 1DVBS framework to match the observed SOA yields for a suite high- $\mathrm{NO}_{\mathrm{x}} n$-alkane $+\mathrm{OH}$ experiments (with $N_{\tau}<\sim 1.3$ ) in which the $N_{\mathrm{C}}$ of the alkanes was varied, once the differing volatilities of the parent compounds were accounted for.

\subsection{Additional considerations}

\subsubsection{Ageing and heterogeneous oxidation}

The above general discussion of the SOM primarily focused on oxidation over relatively short timescales (i.e. only over a few lifetimes of oxidation). Given sufficient time or sufficiently high $\mathrm{OH}$ concentrations, all of the SOA precursor will react away. At this point it is reactions of the product molecules that lead to continued SOA growth. As fragmentation continues to occur, lower volatility long-chain species are continuously converted into higher volatility short-chain species, which can lead to evaporation of condensed-phase species and a decrease in the particle mass. Additionally, as SOA growth slows heterogeneous reactions will become increasingly important.

Once again, the $N_{\mathrm{C}}=12$ system is used as a test case, with $[\mathrm{HC}]_{0}=10 \mathrm{ppb}$ and $[\mathrm{OH}]=2 \times 10^{6}$ molecules $\mathrm{cm}^{-3}$ and with SOM parameters of $\Delta \mathrm{LVP}=1.6, P_{\text {func }}=[0.33$, $0.33,0.33,0.01]$. The model is run for 20 oxidation lifetimes. Three cases are considered: (1) no fragmentation, (2) $c_{\text {frag }}=0.2$ and (3) $c_{\text {frag }}=0.2$ including heterogeneous chemistry. Case 3 , with heterogeneous chemistry, requires specification of the particle number concentration and the 
$\mathrm{OH}$ uptake coefficient; we assume $10^{4}$ particles $\mathrm{cm}^{-3}$ and $\gamma_{\mathrm{OH}}=1$. The particle size is calculated at each time step from the instantaneous $C_{\mathrm{OA}}$ and particle number concentration, and where monodisperse spherical particles are assumed; the peak particle diameter ranges from $\sim 120 \mathrm{~nm}$ to $200 \mathrm{~nm}$, depending on which case is considered. Results are shown in Fig. 12.

For Case 1 (no fragmentation), the SOA produced rapidly reaches the maximum yield (by around 3 lifetimes) and remains high. The mean $\mathrm{O}: \mathrm{C}$ reaches a minimum of 0.34 at $\sim 1$ lifetime, after which point it very slowly increases to $\sim 0.41$ at 20 lifetimes. For Case $2\left(c_{\text {frag }}=0.2\right)$, somewhat different results are obtained. The $C_{\mathrm{OA}}$ peaks and then decreases as gas-phase reactions convert the molecules to increasingly high-volatility species, thus inducing evaporation of the condensed-phase molecules. However, some of this evaporated mass reacts and is recycled back to the particle phase as higher $\mathrm{O}: \mathrm{C}$ material, leading to an increase in the $\mathrm{O}: \mathrm{C}$ over time, with the $\mathrm{O}: \mathrm{C}$ of Case 2 eventually ending up higher than that of Case 1 . However, this only occurs after a few lifetimes of oxidation, which may correspond to a few days of ageing in the atmosphere (depending on the $[\mathrm{OH}]$ and compound reactivity). Overall, it appears that fragmentation in the gas-phase is, by itself, a relatively inefficient pathway for increasing the $\mathrm{O}: \mathrm{C}$ of $\mathrm{OA}$.

When heterogeneous reactions are included (Case 3 ) there is only a small difference compared to Case 2 when $N_{\tau}<3$. However, at longer oxidation lifetimes heterogeneous reactions lead to (i) increased loss of aerosol mass and (ii) a strong increase in the mean particle $\mathrm{O}: \mathrm{C}$. The additional mass loss is the result of fragmentation reactions in the condensed phase that lead to production of and evaporation of higher volatility products. The increase in $\mathrm{O}: \mathrm{C}$ results from functionalization reactions that add oxygen directly to the particle-phase species. If a smaller value for $\gamma_{\mathrm{OH}}$ is assumed, the timescale at which heterogeneous chemistry becomes important shifts towards longer times, and vice versa. Similarly, if a smaller particle number concentration were assumed, leading to larger particles overall, the influence of heterogeneous reactions is diminished. (Note that if the SOM were fit to chamber or flow-tube experiment data, the measured particle number would be used.) The heterogeneous mechanism in the SOM assumes only 1 oxygen is added per reaction. If a distribution of oxygens were instead assumed added (as in the gas-phase), the $\mathrm{O}: \mathrm{C}$ would increase more rapidly.

These model results compare well with the general behavior observed by Lambe et al. (2012) from experiments where SOA was formed in a flow-tube with a constant $[\mathrm{HC}]_{0}$ but with varying oxidation lifetimes (i.e. $\mathrm{OH}$ exposures). Specifically, Lambe et al. (2012) observed that the aerosol yield initially increased with $\mathrm{OH}$ exposure, but eventually peaked and then decreased; the shape of their observed yield vs. $\mathrm{OH}$ exposure curves is similar to that calculated for Case 3 . Additionally, the shape of the calculated variation of $\mathrm{O}: \mathrm{C}$ with $\mathrm{OH}$ exposure is in general agreement with the Lambe et

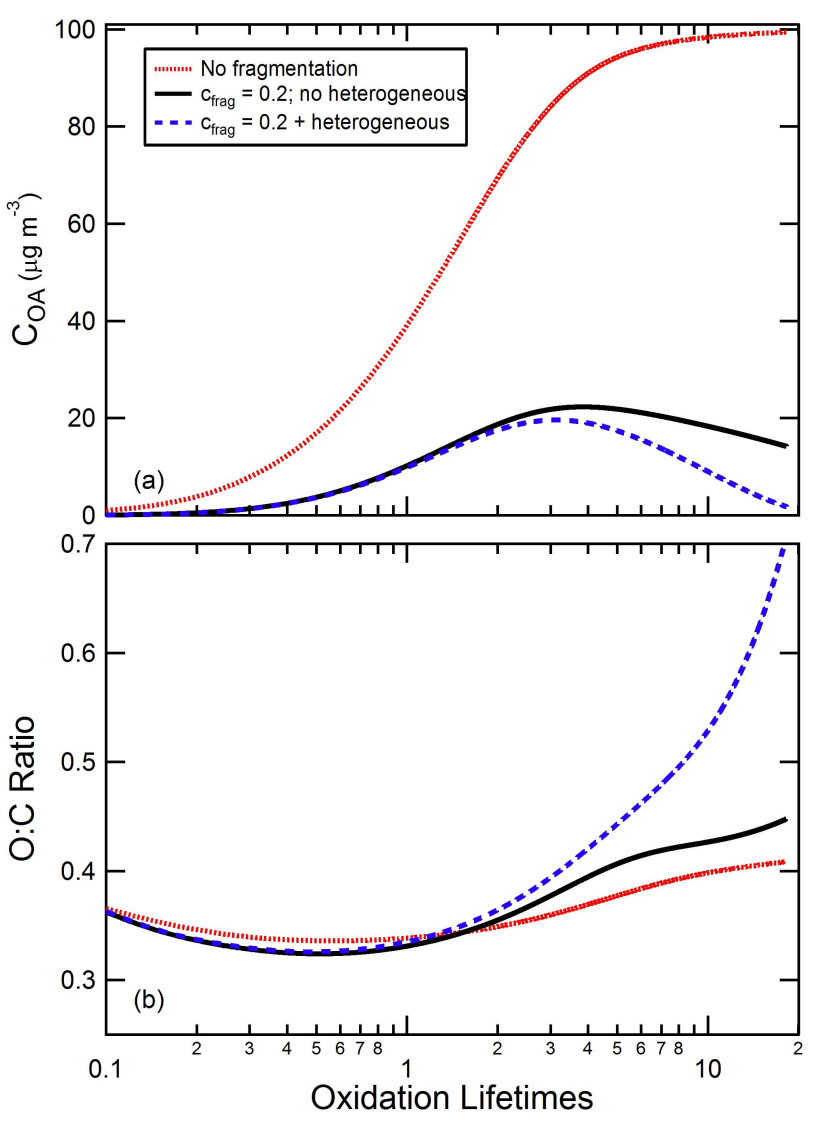

Fig. 12. The variation in the calculated (a) $C_{\mathrm{OA}}$ and (b) $\mathrm{O}: \mathrm{C}$ with the number of SOA precursor oxidation lifetimes for a $N_{\mathrm{C}}=12$ precursor for different reaction conditions (see legend), including heterogeneous reactions with $\mathrm{OH}$.

al. (2012) observations. The SOM results suggest that consideration of heterogeneous reactions at short oxidation lifetimes is not crucial. However, at longer oxidation lifetimes models should include heterogeneous reactions, as some already do (e.g. Jimenez et al., 2009).

\subsubsection{Formation of oxidized organic aerosol: $O$ : C vs. SOA volatility}

Ambient SOA is a complex mixture of compounds. Factor analysis of ambient OA time-series measurements (Ulbrich et al., 2009; Zhang et al., 2011), coupled with estimates of OA volatility (Huffman et al., 2009a; Cappa and Jimenez, 2010) provide some constraints on the likely range of values for $\mathrm{O}: \mathrm{C}$ and volatility of ambient SOA. Factor analysis results suggest that SOA can be equated with a general "oxidized" organic aerosol (OOA) factor, which can be further subdivided into "low volatility" and "semi volatile" components (LV-OOA and SV-OOA, respectively), each with distinct properties (Jimenez et al., 2009). Jimenez et al. (2009) suggest a range of likely values for the $\mathrm{O}: \mathrm{C}$ and $\log C^{*}$ for LV-OOA and SV-OOA (shown in Fig. 13). 


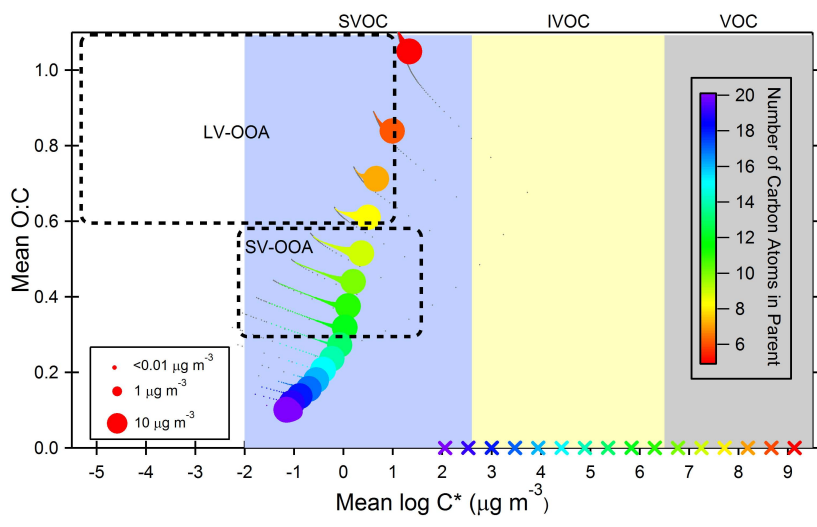

Fig. 13. The evolution of SOA formed from SOA precursor compounds with $5 \leq N_{\mathrm{C}} \leq 20$ over 1 lifetime of oxidation where $10 \mu \mathrm{g} \mathrm{m}^{-3}$ SOA has been formed. Points are colored by the number of atoms comprising the SOA precursor and the symbol size corresponds to the amount of OA formed. The precursor species properties are indicated as $x$ 's. Regions designating LV-OOA and SV-OOA are from Jimenez et al. (2009).

To relate the SOM results to the LV-OOA and SV-OOA categorization of OA, trajectories of the mean $\log C^{*}$ value of the condensed phase products, weighted by mass, have been computed along with the mean $\mathrm{O}: \mathrm{C}$ for precurors of varying $N_{\mathrm{C}}$. Calculations have been carried out for the following reaction conditions: $[\mathrm{OH}]=2 \times 10^{6}$ molecules $\mathrm{cm}^{-3}$, $t=8 \mathrm{~h}, \Delta \mathrm{LVP}=1.6, c_{\text {frag }}=0.2$ and $P_{\text {func }}=[0.33,0.33$, $0.33,0.01]$. The $[\mathrm{HC}]_{0}$ for each $N_{\mathrm{C}}$ was selected to give $C_{\mathrm{OA}}=10 \mu \mathrm{g} \mathrm{m}^{-3}$ at the end of the reaction. Note that the specific values chosen are reasonable mid-range values based on the above determined best-fits to the $n$-alkanes and $\alpha$ pinene and thus, although the specific results depend on the exact parameters, the conclusions should be reasonably general to these types of systems. In general, as OA forms, the mean volatility reaches a minimum where the $\mathrm{O}: \mathrm{C}$ reaches a maximum (Fig. 13). However, both occur when only very little OA has formed. The "fishhook" behavior occurs around the point when OA formation begins in earnest (e.g. $C_{\mathrm{OA}}$ $>0.01 \mu \mathrm{g} \mathrm{m}^{-3}$ ), which is when more than just the very lowest volatility components begin to contribute in a substantial way (in a similar manner to what was shown in Fig. 3a).

Although small $N_{\mathrm{C}}$ compounds $\left(N_{\mathrm{C}}<\sim 9\right)$ can lead to OA with large $\mathrm{O}: \mathrm{C}$, the SOM indicates that gas-phase reactions, coupled with equilibrium gas-particle partitioning theory, does not generally lead to the production of material with sufficiently low volatility so-as to be readily classified as LVOOA; the mean volatility for the SOA that has high O:C tends to lie on the high side of the LV-OOA category. This suggests that condensed-phase reactions not considered in the SOM (such as oligomerization or aqueous phase processing) could be required to produce aerosol with sufficiently low volatility to be considered LV-OOA. In the case of SVOOA formation, compounds with around $9 \leq N_{\mathrm{C}} \leq 12$ can produce SOA with both the appropriate $\mathrm{O}: \mathrm{C}$ and volatility. It is possible to shift these ranges of $N_{\mathrm{C}}$ somewhat by altering the assumed $\triangle \mathrm{LVP}$, with lower values leading to higher $\mathrm{O}: \mathrm{C}$ for a given $N_{\mathrm{C}}$ species, although as $\triangle \mathrm{LVP}$ is decreased, the model SOA volatility increases.

Two caveats to the above conclusions should be considered. First, the SOM utilizes a reasonable, albeit simplified scheme to represent the detailed chemistry that actually occurs in the gas-phase and assumes that there are specific relationships between oxygen addition and volatility. If reactions occur that can add oxygen more rapidly than considered in the SOM (for example, $>5$ oxygens per reaction) or for which the assumed range of the volatility/oxygen relationship does not hold (e.g. $\triangle \mathrm{LVP}<0.7$ ) it is possible to obtain SOA with higher $\mathrm{O}: \mathrm{C}$ values than the SOM predicts. Additionally, if the SOM parameters, assumed here to be constant for a given reaction, actually vary dramatically with composition then different results may be obtained. Second, if there is a substantial kinetic limitation to condensation (i.e. a failure of the instantaneous equilibrium partitioning assumption), then it may be possible for a molecule to undergo a greater number of gas-phase reactions prior to condensation, which would allow for an increase in the $\mathrm{O}: \mathrm{C}$ and a decrease in the volatility beyond those predicted by the SOM. Such considerations may be particularly important when simulating SOA formation for compounds that are more structurally complex than those considered here, such as sesquiterpenes $\left(N_{\mathrm{C}}=15\right.$ with 2 double bonds) for which higher $\mathrm{O}: \mathrm{C}$ values than expected have been observed (Chen et al., 2011).

\subsubsection{Oxygenated SOA precursors}

Some SOA precursors emitted to the atmosphere are likely to contain oxygen atoms. Above, only precursors with zero oxygen atoms have been considered. Here, the influence of oxygen atoms on a SOA precursor on the SOM results is considered. SOA formation has been simulated over 10 lifetimes of oxidation for a $N_{\mathrm{C}}=12$ hydrocarbon that initially contains 0,1 or 2 oxygen atoms. (Note that lifetimes have been calculated based on the reactivity of the specific parent hydrocarbon.) The model parameters used are: $\Delta \mathrm{LVP}=1.6$, $c_{\text {frag }}=0.2$ and $P_{\text {func }}=[0.33,0.33,0.33,0.01]$, with heterogeneous chemistry excluded for simplicity (the general conclusions do not depend on this). A fixed $[\mathrm{HC}]_{0}=70 \mu \mathrm{g} \mathrm{m}^{-3}$ has been used (equal to $10 \mathrm{ppb}$ of a saturated $N_{\mathrm{C}}=12$ hydrocarbon). We have additionally run the SOM for a $N_{\mathrm{C}}=9$ precursor that has 1 oxygen atom, which has a predicted volatility $\left(\log C^{*}=5.6\right)$ very similar to the $N_{\mathrm{C}}=12$ precursor with zero oxygens $\left(\log C^{*}=5.8\right)$ when $\Delta \mathrm{LVP}=1.6$.

The addition of oxygen atoms to the parent hydrocarbon leads to more rapid production of SOA (Fig. 14). The oxygenated precursors have a slightly greater peak $C_{\mathrm{OA}}$, compared to the non-oxygen containing parent species, while the calculated O : C differs only slightly between the three $N_{\mathrm{C}}=$ 12 cases. These results indicate that the addition of oxygen 

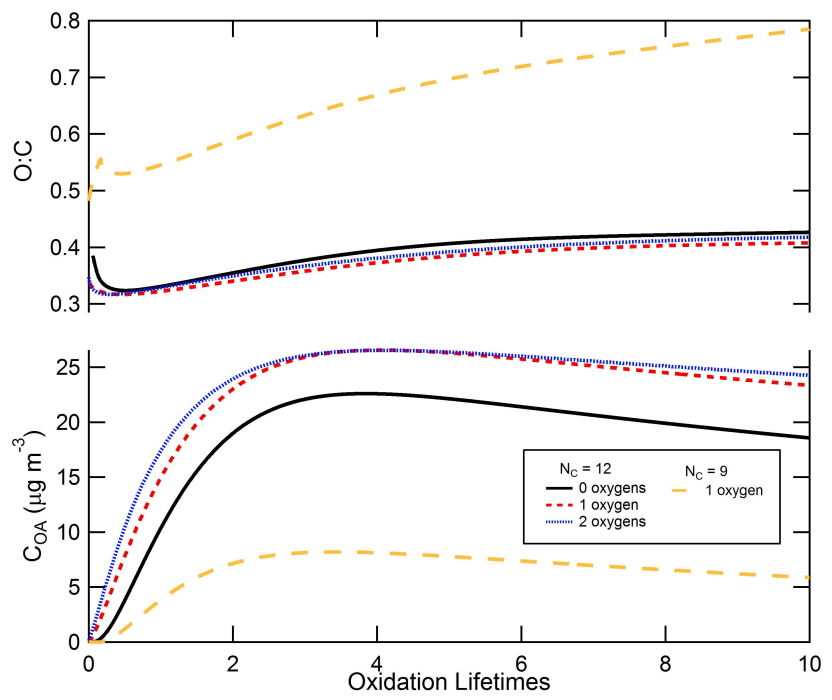

Fig. 14. The evolution of the calculated $C_{\mathrm{OA}}$ (bottom) and $\mathrm{O}: \mathrm{C}$ (top) with oxidation lifetime for a $N_{\mathrm{C}}=12$ precursor species that contains 0,1 or 2 oxygen atoms, or for a $N_{\mathrm{C}}=9$ precursor that contains 1 oxygen atom.

atoms to precursor species (for a constant $N_{\mathrm{C}}$ ) does not have a large effect on the SOA formed, either in terms of mass or $\mathrm{O}: \mathrm{C}$, although does influence the formation timescale somewhat.

Reaction of the $N_{\mathrm{C}}=9$ precursor with 1 oxygen yields $\sim 60 \%$ less $\mathrm{OA}$ than the non-oxygenated $N_{\mathrm{C}}=12$ precursor that is of comparable volatility. Additionally, the $\mathrm{O}: \mathrm{C}$ of the OA formed by the smaller $N_{\mathrm{C}}$ precursor is substantially higher than that of the larger $N_{\mathrm{C}}$ precursor, consistent with our earlier results that $\mathrm{O}: \mathrm{C}$ is determined in large part by $N_{\mathrm{C}}$. An interesting difference is found if the same calculations are performed without fragmentation $\left(c_{\text {frag }}=0\right)$. Now, the amount of OA produced by $N_{\tau} \sim 3$ is very similar for the oxygenated $N_{\mathrm{C}}=9$ and non-oxygenated $N_{\mathrm{C}}=12$ precursors (although the $\mathrm{O}: \mathrm{C}$ remain quite different). This suggests that differences between the SOA mass (or yield) formed from precursors with different numbers of initial carbon and oxygen atoms but similar volatilities results primarily from differences in fragmentation. Chacon-Madrid and Donahue (2011) reported aerosol growth curves (yield vs. $C_{\mathrm{OA}}$ ) for oxygenated and non-oxygenated precursor hydrocarbons with similar volatilities but different $N_{\mathrm{C}}$. The SOM results are generally consistent with their observations, where a decreased yield was observed for the smaller oxygenated precursors. They similarly concluded that fragmentation plays a key role in determining the aerosol yields.

\section{Implications and conclusions}

The development of a parameterized kinetic model of SOA formation that accounts for the multi-generational addition of oxygen, fragmentation and volatility within the general framework of gas-particle equilibrium partitioning theory, termed the statistical oxidation model, has been presented. The SOM provides an explicitly kinetic framework and can be used to fit data from laboratory SOA formation experiments. Additionally, some general insights into the formation of SOA can be obtained from the SOM, within the constraints of the model formulation. Results from the SOM indicate that the particle-phase $\mathrm{O}: \mathrm{C}$ is strongly dependent on the number of carbons comprising the gas-phase SOA precursor, with the nature of the functional groups added (i.e. the $\triangle$ LVP parameter) playing a secondary role. The inclusion of fragmentation does not have a strong influence on the predicted $\mathrm{O}: \mathrm{C}$, at least when only gas-phase processing is considered. This is a consequence of the strong relationship between the number of oxygen-containing functional groups, $N_{\mathrm{C}}$ and volatility. Although fragmentation does not have a strong influence on $\mathrm{O}: \mathrm{C}$, fragmentation is nonetheless an important aspect of the SOA formation process given its strong influence on aerosol yields. Gas-phase mechanisms have been shown to have difficulty forming OA that has very low volatility (i.e. $\log C^{*}<-1$ ), which is thought to be a key characteristic of "OOA", particularly "LV-OOA". Consideration of heterogeneous $\mathrm{OH}$ reactions are found to be most important when the number of oxidation lifetimes is $>3$.

The recent push towards model development that incorporates tracking of average particle properties, such as $\mathrm{O}: \mathrm{C}$ and volatility, in addition to the extensive property $C_{\mathrm{OA}}$ is useful, as it helps to constrain models in terms of whether the fundamental processes governing SOA formation are being represented in a sufficiently realistic manner. However, care must be taken because it is possible to construct models with composition/volatility relationships that deviate substantially from physical understanding but that can yield results that appear to match observations (e.g. Hodzic et al., 2010; Dzepina et al., 2011; Murphy et al., 2011). (For example, an assumption of an increase in mass by $40 \%$ per reaction due to oxygen addition, as in these studies, corresponds to an addition of $\sim 5$ oxygens per reaction for a $\mathrm{C}_{15}$ hydrocarbon but only 3 oxygens per reaction for a $\mathrm{C}_{9}$ hydrocarbon. If this is assumed to correspond to the same change in $C^{*}$ per reaction for both species (e.g. 2 orders of magnitude), this suggests that the reaction pathways for these two molecules provide fundamentally different $\triangle \mathrm{LVP}$ per oxygen relationships, corresponding to $\triangle \mathrm{LVP}=0.4$ or $\Delta \mathrm{LVP}=0.7$ for $\mathrm{C}_{15}$ and $\mathrm{C}_{9}$, respectively, both of which are much lower than what is physically likely. Assuming instead a mass increase of $7.5 \%$ per reaction with a decrease in $C^{*}$ of 1 order of magnitude corresponds to the addition of 1 and 0.6 oxygens per reaction and $\triangle \mathrm{LVP}=1$ and $\triangle \mathrm{LVP}=1.7$ for $\mathrm{C}_{15}$ and $\mathrm{C}_{9}$, respectively.) Additionally, multi-generational oxidation of "traditional" SOA precursor species should be incorporated into models (Tsimpidi et al., 2010; Dzepina et al., 2011), as opposed to static yield approaches that assume that products do not react. In particular, it is not appropriate to exclude 
such species (e.g. toluene, $\alpha$-pinene) from multi-generational oxidation schemes while allowing for multi-generational oxidation of "non-traditional" IVOC and SVOC species (e.g. Shrivastava et al., 2011). To do so can unfairly increase the aerosol yields from IVOC and SVOC species over traditional species, especially on long timescales (e.g. multiple days of ageing). For example, Dzepina et al. (2011) found that if both IVOC/SVOC and traditional VOC species are allowed to age for 3 days (i.e. undergo multi-generation oxidation) the ratio between the SOA mass formed from IVOC/SVOC and traditional VOCs is $\sim 1.2$, whereas if only IVOC/SVOC species are allowed to age while traditional VOCs are assumed to have static yields the ratio is $\sim 7$.

Not considered in the current implementation of the SOM are condensed-phase reactions. That the volatility of model SOA tends to be substantially higher than that of ambient OA, especially LV-OOA (Cappa and Jimenez, 2010) suggests that condensed phase reactions may play a key role. Such reactions may or may not involve the aerosol aqueous phase. Condensed-phase oligomerization reactions are a likely explanation for the apparently low volatility of chamber SOA, independent of $N_{\mathrm{C}}$ and $\mathrm{O}: \mathrm{C}$ considerations (although chamber SOA is often still more volatile than ambient OA; Huffman et al., 2009b). Condensed phase oligomerization reactions can have varying influence on the particle $\mathrm{O}: \mathrm{C}$ depending on the specific chemical pathway (e.g. aldol condensation vs. ester formation). Most oligomerization reactions will tend to either maintain or decrease the $\mathrm{O}: \mathrm{C}$, although hydration reactions can lead to oxygen addition. Aqueous phase oxidation reactions can lead to substantial increases in $\mathrm{O}: \mathrm{C}$, as has been observed for reactions involving phenolic compounds (Sun et al., 2010). The SOM indicates that the inclusion of fragmentation does not lead to substantial increases in the $\mathrm{O}: \mathrm{C}$ of SOA from gas-phase processing alone. However, if aqueous phase reactions increase the uptake and conversion into SOA of the small, highly volatile fragmentation products then fragmentation may yet be a pathway towards higher O : C SOA. Most laboratory SOA growth experiments are typically conducted under low RH conditions, which suggests that for such experiments this potential pathway will likely be small.

The SOM is inherently a kinetic, multi-generational formulation of OA formation that intrinsically accounts for the evolution of the system with time. The SOM can be fit to individual chamber experiments by tuning of the individual parameters. The tunable parameters derived here can be considered as analogs of traditional aerosol yield/volatility parameters (Odum et al., 1996; Donahue et al., 2006), but contain within them important information about the kinetics, in particular the role of fragmentation. Because the distribution of "molecules" in the SOM is framed as a matrix of oxygen and carbon atoms, it provides a natural framework for the simulation of multi-generational oxidation when the intensive parameter $\mathrm{O}: \mathrm{C}$ is a desired model output. The simultaneous oxidation of multiple compounds can be easily incorpo- rated within the modeling framework simply by adding precursors to the appropriate $N_{\mathrm{C}} / N_{\mathrm{O}}$ cell. Furthermore, one can envision future developments that, for example, include an "oligomerization" operator to account for condensed phase accretion reactions or the conversion of OA to a highly viscous "glassy" phase (Virtanen et al., 2010; Cappa and Wilson, 2011; Koop et al., 2011; Vaden et al., 2011).

\section{Supplementary material related to this article is available online at: http://www.atmos-chem-phys.net/12/ 9505/2012/acp-12-9505-2012-supplement.pdf.}

Acknowledgements. The authors thank Jesse Kroll (MIT), Kelly Daumit (MIT) and John Seinfeld (Caltech) for useful discussions, Sally Ng (Georgia Tech) for the $\alpha$-pinene $+\mathrm{OH}$ photooxidation data and the ACPD reviewers and commentators for their suggestions. CDC was funded by the U.S. National Science Foundation (ATM-1151062) and KRW by the Director, Office of Energy Research, Office of Basic Energy Sciences, Chemical Sciences Division of the U.S. Department of Energy under Contract No. DE-AC02-05CH11231.

Edited by: M. K. Dubey

\section{References}

Aiken, A. C., Decarlo, P. F., Kroll, J. H., Worsnop, D. R., Huffman, J. A., Docherty, K. S., Ulbrich, I. M., Mohr, C., Kimmel, J. R., Sueper, D., Sun, Y., Zhang, Q., Trimborn, A., Northway, M., Ziemann, P. J., Canagaratna, M. R., Onasch, T. B., Alfarra, M. R., Prevot, A. S. H., Dommen, J., Duplissy, J., Metzger, A., Baltensperger, U., and Jimenez, J. L.: O/C and OM/OC ratios of primary, secondary, and ambient organic aerosols with highresolution time-of-flight aerosol mass spectrometry, Environ. Sci. Technol., 42, 4478-4485, doi:10.1021/es703009q, 2008.

Aumont, B., Szopa, S., and Madronich, S.: Modelling the evolution of organic carbon during its gas-phase tropospheric oxidation: development of an explicit model based on a self generating approach, Atmos. Chem. Phys., 5, 2497-2517, doi:10.5194/acp-52497-2005, 2005.

Barsanti, K. C., Smith, J. N., and Pankow, J. F.: Application of the $\mathrm{np}+\mathrm{mP}$ modeling approach for simulating secondary organic particulate matter formation from $\alpha$-pinene oxidation, Atmos. Environ., 45, 6812-6819, doi:10.1016/j.atmosenv.2011.01.038, 2011.

Bertram, A. K., Ivanov, A. V., Hunter, M., Molina, L. T., and Molina, M. J.: The reaction probability of $\mathrm{OH}$ on organic surfaces of tropospheric interest, J. Phys. Chem. A, 105, 9415-9421, doi:10.1021/jp0114034, 2001.

Camredon, M., Aumont, B., Lee-Taylor, J., and Madronich, S.: The SOA/VOC/NO $\mathrm{N}_{\mathrm{x}}$ system: an explicit model of secondary organic aerosol formation, Atmos. Chem. Phys., 7, 5599-5610, doi:10.5194/acp-7-5599-2007, 2007. 
Cappa, C. D. and Jimenez, J. L.: Quantitative estimates of the volatility of ambient organic aerosol, Atmos. Chem. Phys., 10, 5409-5424, doi:10.5194/acp-10-5409-2010, 2010.

Cappa, C. D. and Wilson, K. R.: Evolution of organic aerosol mass spectra upon heating: implications for OA phase and partitioning behavior, Atmos. Chem. Phys., 11, 1895-1911, doi:10.5194/acp11-1895-2011, 2011.

Cappa, C. D., Lovejoy, E. R., and Ravishankara, A. R.: Determination of Evaporation Rates and Vapor Pressures of Very Low Volatility Compounds: A Study of the C4-C10 and C12 Dicarboxylic Acids, J. Phys. Chem. A, 111, 3099-3109, 2007.

Cappa, C. D., Lovejoy, E. R., and Ravishankara, A. R.: Evaporation Rates and Vapor Pressures of the Even-Numbered C8C18 Monocarboxylic Acids, J. Phys. Chem. A, 112, 3959-3964, doi:10.1021/Jp710586m, 2008.

Chacon-Madrid, H. J. and Donahue, N. M.: Fragmentation vs. functionalization: chemical aging and organic aerosol formation, Atmos. Chem. Phys., 11, 10553-10563, doi:10.5194/acp11-10553-2011, 2011.

Che, D. L., Smith, J. D., Leone, S. R., Ahmed, M., and Wilson, K. R.: Quantifying the reactive uptake of $\mathrm{OH}$ by organic aerosols in a continuous flow stirred tank reactor, Phys. Chem. Chem. Phys., 11, 7885-7895, doi:10.1039/B904418C, 2009.

Chen, Q., Liu, Y., Donahue, N. M., Shilling, J. E., and Martin, S. T.: Particle-Phase Chemistry of Secondary Organic Material: Modeled Compared to Measured O : C and H : C Elemental Ratios Provide Constraints, Environ. Sci. Technol., 45, 4763-4770, doi:10.1021/es104398s, 2011.

Chhabra, P. S., Ng, N. L., Canagaratna, M. R., Corrigan, A. L., Russell, L. M., Worsnop, D. R., Flagan, R. C., and Seinfeld, J. H.: Elemental composition and oxidation of chamber organic aerosol, Atmos. Chem. Phys., 11, 8827-8845, doi:10.5194/acp-11-88272011, 2011.

de Gouw, J. A., Middlebrook, A. M., Warneke, C., Goldan, P. D., Kuster, W. C., Roberts, J. M., Fehsenfeld, F. C., Worsnop, D. R., Canagaratna, M. R., Pszenny, A. A. P., Keene, W. C., Marchewka, M., Bertman, S. B., and Bates, T. S.: Budget of organic carbon in a polluted atmosphere: Results from the New England Air Quality Study in 2002, J. Geophys. Res., 110, D16305, doi:10.1029/2004JD005623, 2005.

Donahue, N. M., Robinson, A. L., Stanier, C. O., and Pandis, S. N.: Coupled partitioning, dilution, and chemical aging of semivolatile organics, Environ. Sci. Technol., 40, 2635-2643, doi:10.1021/es052297c, 2006.

Donahue, N. M., Epstein, S. A., Pandis, S. N., and Robinson, A. L.: A two-dimensional volatility basis set: 1. organic-aerosol mixing thermodynamics, Atmos. Chem. Phys., 11, 3303-3318, doi:10.5194/acp-11-3303-2011, 2011.

Dzepina, K., Volkamer, R. M., Madronich, S., Tulet, P., Ulbrich, I. M., Zhang, Q., Cappa, C. D., Ziemann, P. J., and Jimenez, J. L.: Evaluation of recently-proposed secondary organic aerosol models for a case study in Mexico City, Atmos. Chem. Phys., 9, 5681-5709, doi:10.5194/acp-9-5681-2009, 2009.

Dzepina, K., Cappa, C. D., Volkamer, R. M., Madronich, S., DeCarlo, P. F., Zaveri, R. A., and Jimenez, J. L.: Modeling the Multiday Evolution and Aging of Secondary Organic Aerosol During MILAGRO 2006, Environ. Sci. Technol., 45, 3496-3503, doi:10.1021/es103186f, 2011.
George, I. J., Vlasenko, A., Slowik, J. G., Broekhuizen, K., and Abbatt, J. P. D.: Heterogeneous oxidation of saturated organic aerosols by hydroxyl radicals: uptake kinetics, condensed-phase products, and particle size change, Atmos. Chem. Phys., 7, 41874201, doi:10.5194/acp-7-4187-2007, 2007.

Gill, K. J. and Hites, R. A.: Rate Constants for the Gas-Phase Reactions of the Hydroxyl Radical with Isoprene, $\alpha$ - and $\beta$-Pinene, and Limonene as a Function of Temperature, J. Phys. Chem. A, 106, 2538-2544, doi:10.1021/jp013532q, 2002.

Grieshop, A. P., Logue, J. M., Donahue, N. M., and Robinson, A. L.: Laboratory investigation of photochemical oxidation of organic aerosol from wood fires 1: measurement and simulation of organic aerosol evolution, Atmos. Chem. Phys., 9, 1263-1277, doi:10.5194/acp-9-1263-2009, 2009.

Heald, C. L., Jacob, D. J., Park, R. J., Russell, L. M., Huebert, B. J., Seinfeld, J. H., Liao, H., and Weber, R. J.: A large organic aerosol source in the free troposphere missing from current models, Geophys. Res. Lett., 32, L18809, doi:18810.11029/12005GL023831, 2005.

Heald, C. L., Kroll, J. H., Jimenez, J. L., Docherty, K. S., DeCarlo, P. F., Aiken, A. C., Chen, Q., Martin, S. T., Farmer, D. K., and Artaxo, P.: A simplified description of the evolution of organic aerosol composition in the atmosphere, Geophys. Res. Lett., 37, L08803, doi:10.1029/2010g1042737, 2010.

Hearn, J. D. and Smith, G. D.: A mixed-phase relative rates technique for measuring aerosol reaction kinetics, Geophys. Res. Lett., 33, L17805, doi:10.1029/2006g1026963, 2006.

Hearn, J. D., Renbaum, L. H., Wang, X., and Smith, G. D.: Kinetics and products from reaction of $\mathrm{Cl}$ radicals with dioctyl sebacate (DOS) particles in O2: a model for radical-initiated oxidation of organic aerosols, Phys. Chem. Chem. Phys., 9, 4803-4813, doi:10.1039/b707523e, 2007.

Hildebrandt, L., Donahue, N. M., and Pandis, S. N.: High formation of secondary organic aerosol from the photo-oxidation of toluene, Atmos. Chem. Phys., 9, 2973-2986, doi:10.5194/acp-92973-2009, 2009.

Hodzic, A., Jimenez, J. L., Madronich, S., Canagaratna, M. R., DeCarlo, P. F., Kleinman, L., and Fast, J.: Modeling organic aerosols in a megacity: potential contribution of semi-volatile and intermediate volatility primary organic compounds to secondary organic aerosol formation, Atmos. Chem. Phys., 10, 5491-5514, doi:10.5194/acp-10-5491-2010, 2010.

Huffman, J. A., Docherty, K. S., Aiken, A. C., Cubison, M. J., Ulbrich, I. M., DeCarlo, P. F., Sueper, D., Jayne, J. T., Worsnop, D. R., Ziemann, P. J., and Jimenez, J. L.: Chemically-resolved aerosol volatility measurements from two megacity field studies, Atmos. Chem. Phys., 9, 7161-7182, doi:10.5194/acp-9-71612009, 2009a.

Huffman, J. A., Docherty, K. S., Mohr, C., Cubison, M. J., Ulbrich, I. M., Ziemann, P. J., Onasch, T. B., and Jimenez, J. L.: Chemically-Resolved volatility measurments of organic aerosol from different sources, Environ. Sci. Technol., 43, 5351-5357, doi:10.1021/es803539d, 2009b.

IPCC: Climate Change: The Physical Science Basis - Contribution of Working Group I to the Fourth Assessment Report of the Intergovernmental Panel on Climate Change, edited by: Solomon, S., Qin, D., and Manning, M., Cambridge University Press, Cambridge, 996 pp., 2007. 
Jacobson, M. C., Hansson, H. C., Noone, K. J., and Charlson, R. J.: Organic atmospheric aerosols: Review and state of the science, Rev. Geophys., 38, 267-294, doi:10.1029/1998RG000045, 2000.

Jaoui, M. and Kamens, R. M.: Gaseous and Particulate Oxidation Products Analysis of a Mixture of $\alpha$-pinene $+\beta$-pinene $/ \mathrm{O}_{3} /$ Air in the Absence of Light and $\alpha$-pinene $+\beta$-pinene/ $/ \mathrm{NO}_{\mathrm{x}} / \mathrm{Air}$ in the Presence of Natural Sunlight, J. Atmos. Chem., 44, 259-297, doi:10.1023/a:1022977427523, 2003.

Jathar, S. H., Farina, S. C., Robinson, A. L., and Adams, P. J.: The influence of semi-volatile and reactive primary emissions on the abundance and properties of global organic aerosol, Atmos. Chem. Phys., 11, 7727-7746, doi:10.5194/acp-11-77272011, 2011.

Jimenez, J. L., Canagaratna, M. R., Donahue, N. M., Prevot, A. S. H., Zhang, Q., Kroll, J. H., DeCarlo, P. F., Allan, J. D., Coe, H., Ng, N. L., Aiken, A. C., Docherty, K. S., Ulbrich, I. M., Grieshop, A. P., Robinson, A. L., Duplissy, J., Smith, J. D., Wilson, K. R., Lanz, V. A., Hueglin, C., Sun, Y. L., Tian, J., Laaksonen, A., Raatikainen, T., Rautiainen, J., Vaattovaara, P., Ehn, M., Kulmala, M., Tomlinson, J. M., Collins, D. R., Cubison, M. J., Dunlea, E. J., Huffman, J. A., Onasch, T. B., Alfarra, M. R., Williams, P. I., Bower, K., Kondo, Y., Schneider, J., Drewnick, F., Borrmann, S., Weimer, S., Demerjian, K., Salcedo, D., Cottrell, L., Griffin, R., Takami, A., Miyoshi, T., Hatakeyama, S., Shimono, A., Sun, J. Y., Zhang, Y. M., Dzepina, K., Kimmel, J. R., Sueper, D., Jayne, J. T., Herndon, S. C., Trimborn, A. M., Williams, L. R., Wood, E. C., Middlebrook, A. M., Kolb, C. E., Baltensperger, U., and Worsnop, D. R.: Evolution of organic aerosols in the atmosphere, Science, 326, 1525-1529, doi:10.1126/science.1180353, 2009.

Johnson, D., Utembe, S. R., Jenkin, M. E., Derwent, R. G., Hayman, G. D., Alfarra, M. R., Coe, H., and McFiggans, G.: Simulating regional scale secondary organic aerosol formation during the TORCH 2003 campaign in the southern UK, Atmos. Chem. Phys., 6, 403-418, doi:10.5194/acp-6-403-2006, 2006.

Jordan, C. E., Ziemann, P. J., Griffin, R. J., Lim, Y. B., Atkinson, R., and Arey, J.: Modeling SOA formation from OH reactions with C8-C17 n-alkanes, Atmos. Environ., 42, 8015-8026, doi:10.1016/j.atmosenv.2008.06.017, 2008.

Kanakidou, M., Seinfeld, J. H., Pandis, S. N., Barnes, I., Dentener, F. J., Facchini, M. C., Van Dingenen, R., Ervens, B., Nenes, A., Nielsen, C. J., Swietlicki, E., Putaud, J. P., Balkanski, Y., Fuzzi, S., Horth, J., Moortgat, G. K., Winterhalter, R., Myhre, C. E. L., Tsigaridis, K., Vignati, E., Stephanou, E. G., and Wilson, J.: Organic aerosol and global climate modelling: a review, Atmos. Chem. Phys., 5, 1053-1123, doi:10.5194/acp-5-1053-2005, 2005.

Kessler, S. H., Smith, J. D., Che, D. L., Worsnop, D. R., Wilson, K. R., and Kroll, J. H.: Chemical Sinks of Organic Aerosol: Kinetics and Products of the Heterogeneous Oxidation of Erythritol and Levoglucosan, Environ. Sci. Technol., 44, 7005-7010, doi:10.1021/es101465m, 2010.

Koop, T., Bookhold, J., Shiraiwa, M., and Pöschl, U.: Glass transition and phase state of organic compounds: dependency on molecular properties and implications for secondary organic aerosols in the atmosphere, Phys. Chem. Chem. Phys., 13, 19238-19255, doi:10.1039/c1cp22617g, 2011.

Kroll, J. H. and Seinfeld, J. H.: Chemistry of secondary organic aerosol: Formation and evolution of low-volatility or- ganics in the atmosphere, Atmos. Environ., 42, 3593-3624, doi:10.1016/j.atmosenv.2008.01.003, 2008.

Kroll, J. H., Smith, J. D., Che, D. L., Kessler, S. H., Worsnop, D. R., and Wilson, K. R.: Measurement of fragmentation and functionalization pathways in the heterogeneous oxidation of oxidized organic aerosol, Phys. Chem. Chem. Phys., 11, 8005-8014, doi:10.1039/b905289e, 2009.

Kroll, J. H., Donahue, N. M., Jimenez, J. L., Kessler, S. H., Canagaratna, M. R., Wilson, K. R., Altieri, K. E., Mazzoleni, L. R., Wozniak, A. S., Bluhm, H., Mysak, E. R., Smith, J. D., Kolb, C. E., and Worsnop, D. R.: Carbon oxidation state as a metric for describing the chemistry of atmospheric organic aerosol, Nat. Chem., 3, 133-139, doi:10.1038/nchem.948, 2011.

Kwok, E. S. C. and Atkinson, R.: Estimation of hydroxyl radical reaction rate constants for gas-phase organic compounds using a structure-reactivity relationship: An update, Atmos. Environ., 29, 1685-1695, doi:10.1016/1352-2310(95)00069-b, 1995.

Lambe, A. T., Zhang, J. Y., Sage, A. M., and Donahue, N. M.: Controlled $\mathrm{OH}$ radical production via ozone-alkene reactions for use in aerosol aging studies, Environ. Sci. Technol., 41, 2357-2363, doi:10.1021/es061878e, 2007.

Lambe, A. T., Miracolo, M. A., Hennigan, C. J., Robinson, A. L., and Donahue, N. M.: Effective Rate Constants and Uptake Coefficients for the Reactions of Organic Molecular Markers (nAlkanes, Hopanes, and Steranes) in Motor Oil and Diesel Primary Organic Aerosols with Hydroxyl Radicals, Environ. Sci. Technol., 43, 8794-8800, doi:10.1021/es901745h, 2009.

Lambe, A. T., Onasch, T. B., Croasdale, D. R., Wright, J. P., Martin, A. T., Franklin, J. P., Massoli, P., Kroll, J. H., Canagaratna, M. R., Brune, W. H., Worsnop, D. R., and Davidovits, P.: Transitions from Functionalization to Fragmentation Reactions of Laboratory Secondary Organic Aerosol (SOA) Generated from the OH Oxidation of Alkane Precursors, Environ. Sci. Technol., 46, 5430-5437, doi:10.1021/es300274t, 2012.

Lane, T. E., Donahue, N. M., and Pandis, S. N.: Simulating secondary organic aerosol formation using the volatility basis-set approach in a chemical transport model, Atmos. Environ., 42, 7439-7451, doi:doi:10.1016/j.atmosenv.2008.06.026, 2008.

Larsen, B. R., Di Bella, D., Glasius, M., Winterhalter, R., Jensen, N. R., and Hjorth, J.: Gas-phase $\mathrm{OH}$ oxidation of monoterpenes: Gaseous and particulate products, J. Atmos. Chem., 38, 231-276, doi:10.1023/A:1006487530903, 2001.

Lee-Taylor, J., Madronich, S., Aumont, B., Baker, A., Camredon, M., Hodzic, A., Tyndall, G. S., Apel, E., and Zaveri, R. A.: Explicit modeling of organic chemistry and secondary organic aerosol partitioning for Mexico City and its outflow plume, Atmos. Chem. Phys., 11, 13219-13241, doi:10.5194/acp-1113219-2011, 2011.

Lide, D. R. and Kehiaian, H. V.: CRC handbook of thermophysical and thermochemical data, CRC Press, Boca Raton, x, 518 pp., 1994.

Lim, Y. B. and Ziemann, P. J.: Products and mechanism of secondary organic aerosol formation from reactions of n-alkanes with $\mathrm{OH}$ radicals in the presence of $\mathrm{NO}_{\mathrm{x}}$, Environ. Sci. Technol., 39, 9229-9236, doi:10.1021/es051447g, 2005.

Liu, C. L., Smith, J. D., Che, D. L., Ahmed, M., Leone, S. R., and Wilson, K. R.: The direct observation of secondary radical chain chemistry in the heterogeneous reaction of chlorine atoms with submicron squalane droplets, Phys. Chem. Chem. Phys., 13, 
8993-9007, doi:10.1039/c1cp20236g, 2011.

Loza, C. L., Chan, A. W. H., Galloway, M. M., Keutsch, F. N., Flagan, R. C., and Seinfeld, J. H.: Characterization of Vapor Wall Loss in Laboratory Chambers, Environ. Sci. Technol., 44, 50745078, doi:10.1021/es100727v, 2010.

Matsui, H., Koike, M., Takegawa, N., Kondo, Y., Griffin, R. J., Miyazaki, Y., Yokouchi, Y., and Ohara, T.: Secondary organic aerosol formation in urban air: Temporal variations and possible contributions from unidentified hydrocarbons, J. Geophys. Res., 114, D22207, doi:10.1029/2008jd010164, 2009.

Matsunaga, A. and Ziemann, P. J.: Gas-Wall Partitioning of Organic Compounds in a Teflon Film Chamber and Potential Effects on Reaction Product and Aerosol Yield Measurements, Aerosol Sci. Technol., 44, 881-892, doi:10.1080/02786826.2010.501044, 2010.

McNeill, V. F., Yatavelli, R. L. N., Thornton, J. A., Stipe, C. B., and Landgrebe, O.: Heterogeneous $\mathrm{OH}$ oxidation of palmitic acid in single component and internally mixed aerosol particles: vaporization and the role of particle phase, Atmos. Chem. Phys., 8, 5465-5476, doi:10.5194/acp-8-5465-2008, 2008.

Murphy, B. N., Donahue, N. M., Fountoukis, C., and Pandis, S. N.: Simulating the oxygen content of ambient organic aerosol with the 2D volatility basis set, Atmos. Chem. Phys., 11, 7859-7873, doi:10.5194/acp-11-7859-2011, 2011.

Ng, N. L., Chhabra, P. S., Chan, A. W. H., Surratt, J. D., Kroll, J. H., Kwan, A. J., McCabe, D. C., Wennberg, P. O., Sorooshian, A., Murphy, S. M., Dalleska, N. F., Flagan, R. C., and Seinfeld, J. H.: Effect of $\mathrm{NO}_{\mathrm{x}}$ level on secondary organic aerosol (SOA) formation from the photooxidation of terpenes, Atmos. Chem. Phys., 7, 5159-5174, doi:10.5194/acp-7-5159-2007, 2007a.

Ng, N. L., Kroll, J. H., Chan, A. W. H., Chhabra, P. S., Flagan, R. C., and Seinfeld, J. H.: Secondary organic aerosol formation from m-xylene, toluene, and benzene, Atmos. Chem. Phys., 7, 3909-3922, doi:10.5194/acp-7-3909-2007, 2007b.

Ng, N. L., Canagaratna, M. R., Jimenez, J. L., Chhabra, P. S., Seinfeld, J. H., and Worsnop, D. R.: Changes in organic aerosol composition with aging inferred from aerosol mass spectra, Atmos. Chem. Phys., 11, 6465-6474, doi:10.5194/acp-11-64652011, 2011.

Odum, J. R., Hoffmann, T., Bowman, F., Collins, D., Flagan, R. C., and Seinfeld, J. H.: Gas/particle partitioning and secondary organic aerosol yields, Environ. Sci. Technol., 30, 2580-2585, doi:10.1021/es950943+, 1996.

Pankow, J. F.: An absorption-model of the gas aerosol partitioning involved in the formation of secondary organic aerosol, Atmos. Environ., 28, 189-193, doi:10.1016/1352-2310(94)900949, 1994.

Pankow, J. F. and Asher, W. E.: SIMPOL.1: a simple group contribution method for predicting vapor pressures and enthalpies of vaporization of multifunctional organic compounds, Atmos. Chem. Phys., 8, 2773-2796, doi:10.5194/acp-8-27732008, 2008.

Pankow, J. F. and Barsanti, K. C.: The carbon numberpolarity grid: A means to manage the complexity of the mix of organic compounds when modeling atmospheric organic particulate matter, Atmos. Environ., 43, 2829-2835, doi:10.1016/j.atmosenv.2008.12.050, 2009.

Parikh, H. M., Carlton, A. G., Vizuete, W., and Kamens, R. M.: Modeling secondary organic aerosol using a dynamic partitioning approach incorporating particle aqueous-phase chemistry, Atmos. Environ., 45, 1126-1137, doi:10.1016/j.atmosenv.2010.11.027, 2011.

Presto, A. A., Miracolo, M. A., Donahue, N. M., and Robinson, A. L.: Secondary Organic Aerosol Formation from High- $\mathrm{NO}_{\mathrm{x}}$ Photo-Oxidation of Low Volatility Precursors: n-Alkanes, Environ. Sci. Technol., 44, 2029-2034, doi:10.1021/es903712r, 2010.

Robinson, A. L., Donahue, N. M., Shrivastava, M. K., Weitkamp, E. A., Sage, A. M., Grieshop, A. P., Lane, T. E., Pierce, J. R., and Pandis, S. N.: Rethinking organic aerosols: Semivolatile emissions and photochemical aging, Science, 315, 1259-1262, doi:10.1126/science.1133061, 2007.

Russell, L. M., Bahadur, R., and Ziemann, P. J.: Identifying organic aerosol sources by comparing functional group composition in chamber and atmospheric particles, P. Natl. Acad. Sci., 108, 3516-3521, doi:10.1073/pnas.1006461108, 2011.

Seinfeld, J. H. and Pankow, J. F.: Organic atmospheric particulate material, Annu. Rev. Phys. Chem., 54, 121-140, doi:10.1146/annurev.physchem.54.011002.103756, 2003.

Shrivastava, M., Fast, J., Easter, R., Gustafson Jr., W. I., Zaveri, R. A., Jimenez, J. L., Saide, P., and Hodzic, A.: Modeling organic aerosols in a megacity: comparison of simple and complex representations of the volatility basis set approach, Atmos. Chem. Phys., 11, 6639-6662, doi:10.5194/acp-11-6639-2011, 2011.

Smith, J. D., Kroll, J. H., Cappa, C. D., Che, D. L., Liu, C. L., Ahmed, M., Leone, S. R., Worsnop, D. R., and Wilson, K. R.: The heterogeneous reaction of hydroxyl radicals with submicron squalane particles: a model system for understanding the oxidative aging of ambient aerosols, Atmos. Chem. Phys., 9, 3209-3222, doi:10.5194/acp-9-3209-2009, 2009.

Sun, Y., Zhang, Q., Macdonald, A. M., Hayden, K., Li, S. M., Liggio, J., Liu, P. S. K., Anlauf, K. G., Leaitch, W. R., Steffen, A., Cubison, M., Worsnop, D. R., van Donkelaar, A., and Martin, R. V.: Size-resolved aerosol chemistry on Whistler Mountain, Canada with a high-resolution aerosol mass spectrometer during INTEX-B, Atmos. Chem. Phys., 9, 3095-3111, doi:10.5194/acp9-3095-2009, 2009.

Sun, Y. L., Zhang, Q., Anastasio, C., and Sun, J.: Insights into secondary organic aerosol formed via aqueous-phase reactions of phenolic compounds based on high resolution mass spectrometry, Atmos. Chem. Phys., 10, 4809-4822, doi:10.5194/acp-104809-2010, 2010.

Tsimpidi, A. P., Karydis, V. A., Zavala, M., Lei, W., Molina, L., Ulbrich, I. M., Jimenez, J. L., and Pandis, S. N.: Evaluation of the volatility basis-set approach for the simulation of organic aerosol formation in the Mexico City metropolitan area, Atmos. Chem. Phys., 10, 525-546, doi:10.5194/acp-10-525-2010, 2010.

Ulbrich, I. M., Canagaratna, M. R., Zhang, Q., Worsnop, D. R., and Jimenez, J. L.: Interpretation of organic components from Positive Matrix Factorization of aerosol mass spectrometric data, Atmos. Chem. Phys., 9, 2891-2918, doi:10.5194/acp-9-2891-2009, 2009.

Vaden, T. D., Imre, D., Beránek, J., Shrivastava, M., and Zelenyuk, A.: Evaporation kinetics and phase of laboratory and ambient secondary organic aerosol, P. Natl. Acad. Sci., 108, 2190-2195, doi:10.1073/pnas.1013391108, 2011.

Valorso, R., Aumont, B., Camredon, M., Raventos-Duran, T., Mouchel-Vallon, C., Ng, N. L., Seinfeld, J. H., Lee-Taylor, J., and Madronich, S.: Explicit modelling of SOA formation from a- 
pinene photooxidation: sensitivity to vapour pressure estimation, Atmos. Chem. Phys., 11, 6895-6910, doi:10.5194/acp-11-68952011, 2011.

Virtanen, A., Joutsensaari, J., Koop, T., Kannosto, J., Yli-Pirila, P., Leskinen, J., Makela, J. M., Holopainen, J. K., Poschl, U., Kulmala, M., Worsnop, D. R., and Laaksonen, A.: An amorphous solid state of biogenic secondary organic aerosol particles, Nature, 467, 824-827, 2010.

Volkamer, R., Jimenez, J. L., San Martini, F., Dzepina, K., Zhang, Q., Salcedo, D., Molina, L. T., Worsnop, D. R., and Molina, M. J.: Secondary organic aerosol formation from anthropogenic air pollution: Rapid and higher than expected, Geophys. Res. Lett., 33, L17811, doi:10.1029/2006g1026899, 2006.

Wilson, K. R., Smith, J. D., Kessler, S. H., and Kroll, J. H.: The statistical evolution of multiple generations of oxidation products in the photochemical aging of chemically reduced organic aerosol, Phys. Chem. Chem. Phys., 14, 1468-1479, doi:10.1039/c1cp22716e, 2012.
Wong, J. P. S., Lee, A. K. Y., Slowik, J. G., Cziczo, D. J., Leaitch, W. R., Macdonald, A., and Abbatt, J. P. D.: Oxidation of ambient biogenic secondary organic aerosol by hydroxyl radicals: Effects on cloud condensation nuclei activity, Geophys. Res. Lett., 38, L22805, doi:10.1029/2011g1049351, 2011.

Zhang, Q., Jimenez, J. L., Canagaratna, M. R., Ulbrich, I. M., Ng, N. L., Worsnop, D. R., and Sun, Y. L.: Understanding atmospheric organic aerosols via factor analysis of aerosol mass spectrometry: a review, Anal. Bioanal. Chem., 401, 3045-3067, doi:10.1007/s00216-011-5355-y, 2011.

Ziemann, P. J.: Effects of molecular structure on the chemistry of aerosol formation from the $\mathrm{OH}$-radical-initiated oxidation of alkanes and alkenes, Int. Rev. Phys. Chem., 30, 161-195, doi:10.1080/0144235x.2010.550728, 2011. 